Portland State University

PDXScholar

1991

\title{
Environmental and age differences in the formation of romantic pairs and self-monitoring in adolescents
}

Russell I. Oelheim

Portland State University

Follow this and additional works at: https://pdxscholar.library.pdx.edu/open_access_etds

Part of the Psychology Commons

Let us know how access to this document benefits you.

\section{Recommended Citation}

Oelheim, Russell I., "Environmental and age differences in the formation of romantic pairs and selfmonitoring in adolescents" (1991). Dissertations and Theses. Paper 4430.

https://doi.org/10.15760/etd.6314

This Thesis is brought to you for free and open access. It has been accepted for inclusion in Dissertations and Theses by an authorized administrator of PDXScholar. Please contact us if we can make this document more accessible: pdxscholar@pdx.edu. 
AN ABSTRACT OF THE THESIS OF Russell I. Oelheim for the Master of science in Psychology presented December 11, 1991.

Title: Environmental and Age Differences in the Formation of Romantic Pairs and Self-Monitoring in Adolescents.

APPROVED BY THE MEMBERS OF THE THESIS COMMITTEE:

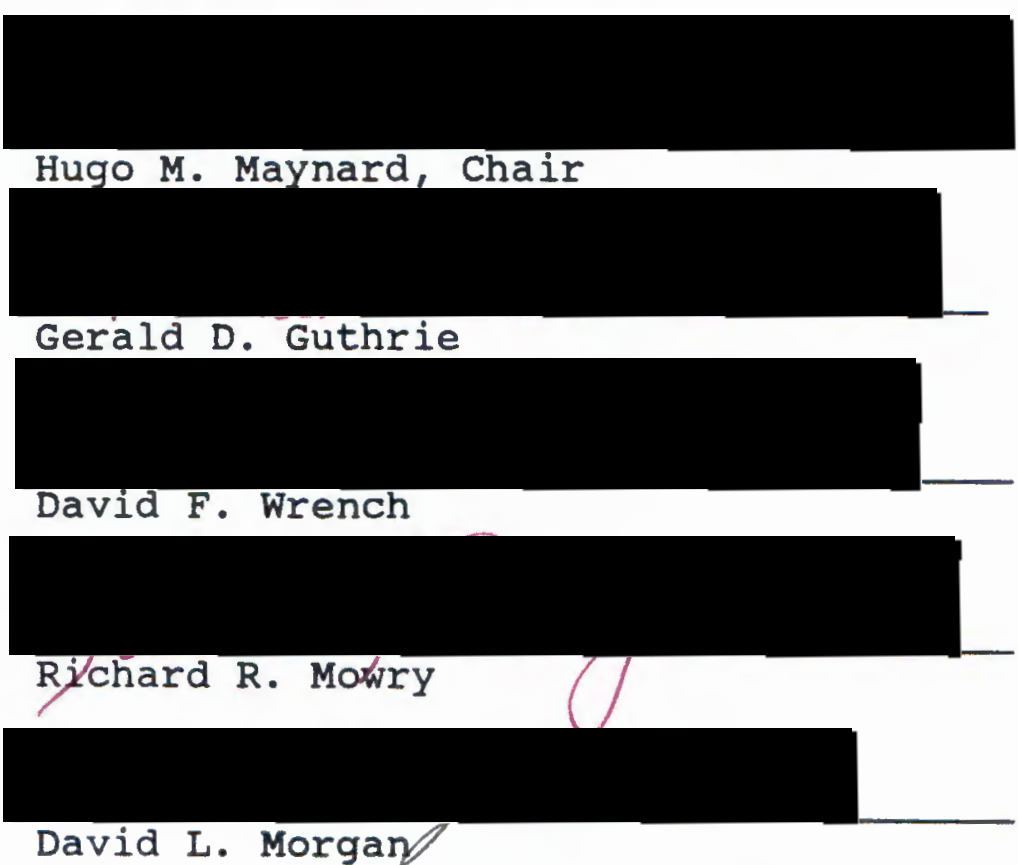

Mark Snyder (1974) in his Self-Monitoring (SM) construct proposed there were two ways in which people might be classified: high and low self-monitors. High SM individuals attend to environmental cues and respond to the 
expectations of a given situation, while low SM individuals respond to their feelings, inner states and personal values. This construct has been extensively researched with adults and children, but not with adolescents.

David Elkind (1979), in his Imaginary Audience (IA) construct, suggested that upon reaching puberty, teenagers become vitally aware of how they are perceived by others. Elkind maintained that girls in early adolescence were more aware of the IA than boys, but that this would even out over time.

It was hypothesized in this study that SM, because of the IA, would be higher in younger adolescents and then drop towards adult levels as age increased. It was also hypothesized that younger girls would have higher levels of SM than younger boys, and that these gender differences would diminish with increasing age. Since SM specifically addressed attending to the environment, and since adolescents in alternative schools and jails were considered to be "streetwise" (i.e. environmentally aware), it was predicted that teenagers in restricted situations would be higher SM than teenagers in regular school.

Procedures consisted of two rounds. In the first, 161 students at four sites were evaluated using snyder's 18item SM scale and a task in which the subject matched male and female targets to make up hypothetical dates based on photographs and bio-sketches. Subjects were also asked to 
select a hypothetical date for themselves. Subjects were considered high SM if they scored high on the SM scale; Snyder's SM construct predicts that high SM subjects use "looks" to make up pairs. There was an overall main effect supporting snyder's SM construct. However, on a site-bysite basis, results were mixed. Age and gender differences were marginally supported. When selecting a hypothetical date for themselves, most subjects chose on the basis of personality.

Snyder predicts that $40 \%$ of subjects will score high on SM and $60 \%$ low. That was true in the incarcerated subjects, but the opposite was observed at all other sites. This led to speculation on whether a certain personality type was more likely to be incarcerated.

The second round consisted of re-interviewing the groups at three of the sites and interviewing a new college-age group. Follow-Up Questionnaires (FUQ) from 209 students were analyzed for a school effect, an experimenter effect, an age effect, and a participation effect. It was found that the college, 12th grade and alternative school students were unguarded in their responses during the first round, while the 9 th graders were not. Following administration of the FUQ, discussion with the 9 th graders revealed that they had just been exposed to curriculum emphasizing personality over looks in date selection, and that there had been no previous exposure to experimental 
procedures, making them apprehensive and cautious about their participation. The other groups, because of exposure to science curricula, or (in the alternative school) because of knowledge of the experimenter, were more unguarded in their responses.

It was concluded that snyder's SM construct had some validity with adolescent groups, but that high SM was much more frequent for both boys and girls than snyder predicted. Environment also may play a greater role than previously shown. The results of the FUQ demonstrated a need for preparing young adolescents before their participation in experimental research. 
ENVIRONMENTAL AND AGE DIFFERENCES IN THE FORMATION OF ROMANTIC PAIRS AND SELF-MONITORING IN ADOLESCENTS

$$
\text { by }
$$

RUSSELL I. OELHEIM

A thesis submitted in partial fulfillment of the requirements for the degree of

\author{
MASTER OF SCIENCE \\ in \\ PSYCHOLOGY
}

Portland State University

1992 
TO THE OFFICE OF GRADUATE STUDIES:

The members of the committee approve the thesis of Russell I. Oelheim presented December 11, 1991.

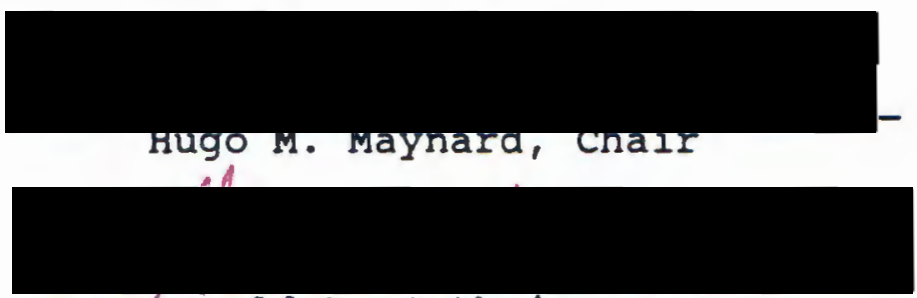

Gerald D. Guthrie

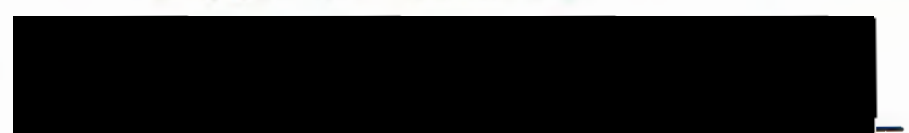

David F. Wrench

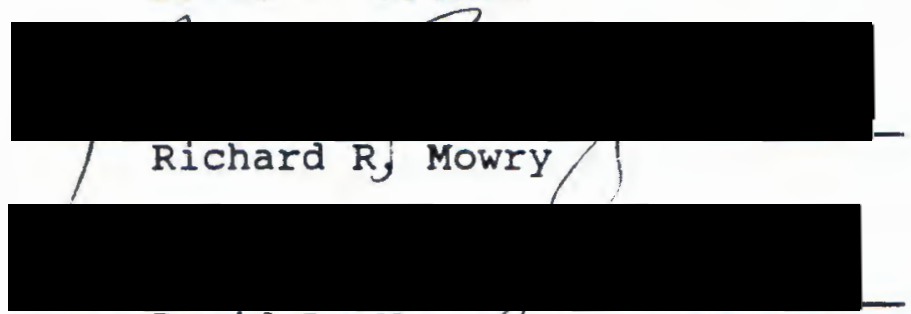

David L. Morgańn

\section{APPROVED :}

cora. B. Sengstake, charr, Department of psychology

c. WIIllam savery, Interim vze provost for Graduate studies and Research 


\section{ACKNOWLEDGEMENTS}

I would like to express my thanks to my thesis committee for their help, concern and guidance, particularly committee chair Dr. Hugo Maynard who calmly kept me on track throughout the development of this project. I would also like to express my appreciation to Dr. Kinderman for his moral support and advice, and to Mr. Richard Mowry for making his school available to the project.

In addition, I would like to specially thank Ed Chrisman, Tricia Diller, Stephanie Lee, Geraldine Poland and Ellery Reed from the Community Psychology Group who helped with this project preparing materials, gathering and processing data, and finally for insightful discussions on procedures and results. I would also like to acknowledge Saul shapiro for his sharing his experiences in the field in terms of interpreting the results.

Finally, I would like to express my appreciation to my wife, Cathy, and my children, Phoebe and sam, for sharing me with the many evening and week-end hours this project demanded, and for their valuable insights when the project dominated discussion around the dining room table. 
TABLE OF CONTENTS

PAGE

ACKNOWLEDGMENTS. ..........................

LIST OF TABLES..........................

CHAPTER

I INTRODUCTION. . . . . . . . . . . . . . . . . . .

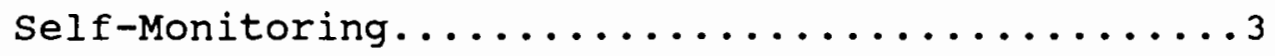

The Visual Nature of Self-Monitoring........6

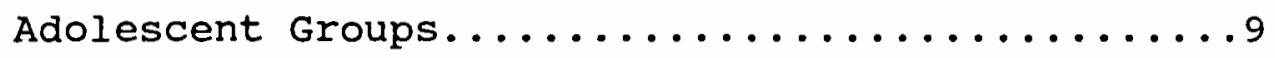

Imaginary Audience................... 10

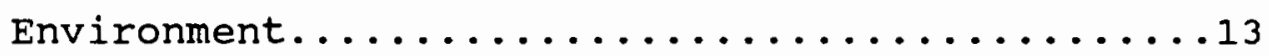

Measures and Hypotheses.................. 15

II METHODS............................. 1

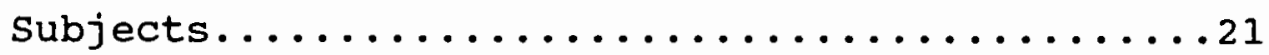

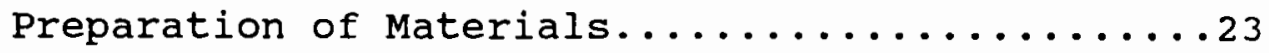

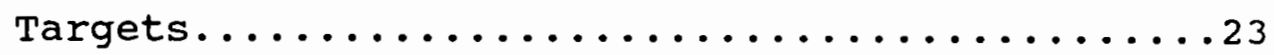

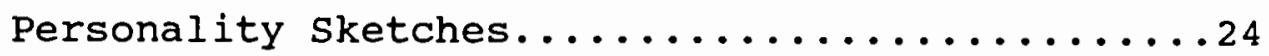

Experimental Procedures..................25

Follow-Up Questionnaire (FUQ) ................

III RESULTS..............................

Follow-Up Questionnaire.................... 
DISCUSSION..............................42

Situational and Age Effects on Respondents.....42 Experiment Effect and School Effect..........48 The Effects of Self-Monitoring..............51

REFERENCES...................................62

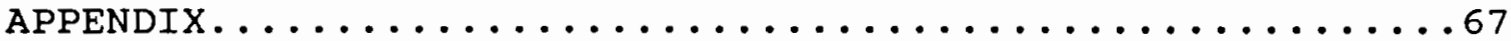




\section{LIST OF TABLES}

TABLES

I Eighteen-Item Measure of Self-Monitoring.........16

II Subject Distribution by School/Program and Grade for the Experimental Procedure and the

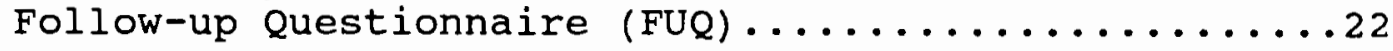

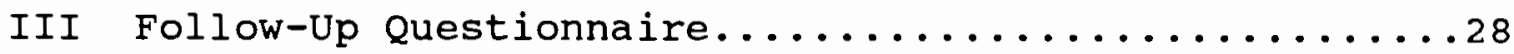

IV Expected Values versus Real Values on

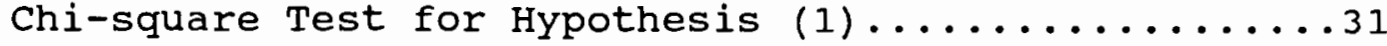

$\mathrm{V}$ Distribution of High versus Low

Self-Monitors at the Different Settings...............

VI Reliability of Panel Attractiveness

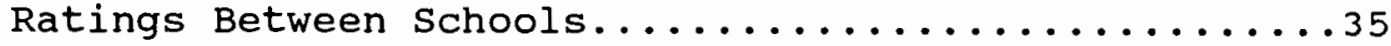

VII School settings versus Levels of Trust...........37 
CHAPTER I

\section{INTRODUCTION}

As I have worked with teenagers in regular and alternative schools, I have often wondered why some children seem to be more prone to displaying behavioral problems. One popular explanation points to the home environment as the place where appropriate behaviors are learned, and strength, discipline and positive self-image are developed to resist negative pressures of the child's peer culture. Bronfenbrenner (1986) very eloquently describes the importance of an enriched home life for the development of a well-adjusted child. Likewise, the Rochester Schools Project (Connell, Deci, Ryan, and Grolnick, 1989) speaks to the need for teachers and staff to "connect" with students, and thus through their interactions help them work through difficult times and make decisions regarding their choices of actions.

Furman (1989) points out that environment plays an important role in the development of an adolescent, especially in the group dynamics that govern interactions between individuals. The environment, which includes the group dynamics, may also have an effect on the emergence of personality traits (Hormuth, 1967; Skinner and Kindermann, 1990) as well as behaviors (Snyder, 1974; Elkind, 1967) 
that are called for in a given situation. In other words, to a certain extent, traits are developed or adopted by the individual to conform to an environmental setting.

Central to these explanations is an assumption that without the influence of parents, teachers and other appropriate adult role models, the demands of the environment will be the dominant factor in how the child elects to behave.

The question of how children connect with adults, peers and their environment is of practical importance and has very serious implications. Single-parent families or families where both parents work are becoming the norm (Bureau of Labor statistics, 1985), and in some areas it is estimated that fifty percent of school age children do not complete school (Bronfenbrenner, 1986). Thus, with a reduction in the amount of time a child may spend with parents, and a lack of contact with teachers the child must learn to respond to the environment based on his or her own experiences. A cycle of behavior in which the child acts more in accordance with the "demand character" (Orne, 1962; Brown, 1988) of the environment can be observed as manifested in the self-Monitor (Snyder, 1974) and Imaginary Audience (Elkind, 1967) constructs.

It is simple to attribute all negative behaviors to the environment and to a lack of appropriate adult/child interactions. Clearly, this is part of the picture and can 
be readily observed. Yet there are those who ignore environmental cues and respond to some internal message. These internal messages may be the concepts of right and wrong, ethics and appropriateness, or they may be the fulfillment of personal needs and expectations. The selfmonitoring construct offers a way to look at both environmental forces and internal messages. Though the behavior of two children may be the same, given the same circumstances, the antecedents and underlying motivations may be quite different. An instrument that sheds some light on how problem children are motivated to make their decisions is something that is always of interest to practitioners, and in this case the self-monitoring construct appears to be worthy of evaluation.

\section{SELF-MONITORING}

What is self-monitoring (SM)? It has been defined by Gangestad and Snyder (1985a) as a class variable that is operational on three dimensions: (1) expressive self-control,

(2) social stage presence, and (3) other-directed self-presentation.

Expressive self-control describes the individual who is adept at presenting one emotional response while perceiving or experiencing another. This may be interpreted as acting ability (Gangestad and Snyder, 1985a). Social stage presence implies that the high SM individual does not feel awkward 
in public situations. This has been interpreted as an extraversion factor (Briggs, Cheek and Buss, 1980). Other-directed behavior could be described as the high SM individual's ability to act in social situations by displaying what others would like or expect one to display.

By contrast, the low SM individual may ask himself in a socially interactive situation, "Who am I and how can I be me in this situation?" In this way the low SM person is also reading the environmental demand characteristics of the situation. However, rather than create a prototypical model of how he should behave, the low self-monitor draws upon an internally generated "enduring self-image or selfconception that represents knowledge of her or his characteristic actions in the behavioral domains most relevant to this situation." (Snyder, 1979).

Snyder continues to describe the high SM individual as one who looks for cues in a situation by which one can determine which responses are appropriate. The high SM individual may look on the behaviors of others with whom he identifies as a guide for expressing himself. Thus, when high SM persons are made uncertain of which emotional reactions are expected, the behaviors of others provide the cues which are used to define their own emotional responses and behaviors (Snyder, 1974; Snyder, 1979; Schachter and Singer, 1962). 
Low SM individuals, by contrast, appear to be able to control their self-representations from within "by their affective states" (Snyder, 1974). The low SM individual is less vigilant to social cues and is less likely to modify self-presentation and behaviors to conform to the demand characteristics of the environment.

The SM construct has been widely investigated (snyder, 1987). Numerous experiments on how the SM trait emerges have been conducted showing that gender and environment do not affect the distribution of high and low SM. However, there is some variability since high SM behaviors change with the way the individual perceives what is socially desirable (Snyder and Gangestad, 1986) and therefore will have different manifestations in different situations, especially as the make-up of a group changes. Thus, different environments may tend to reformulate different standards of social desirability within a group for high SM individuals.

Self-monitoring would probably best be measured by an instrument specifically designed to discriminate individual differences in concern for social appropriateness, sensitivity to the expression and self-presentation in social

situations as cues to social appropriateness of self-expression, and use of these cues as guidelines for monitoring and managing selfpresentation and expressive behavior (snyder, 1974).

There have been three SM scales developed to measure self-monitoring in adults: (1) the original 25-item SM Scale (Snyder, 1974); (2) a 13-item Revised SM Scale 
(Lennox and Wolfe, 1984); and (3) and 18-item Revised SM Scale (Snyder and Gangestad, 1986). Over the 11 year period from 1974 to 1985, the 25-item SM Scale lost some of its predictive power. This led Snyder and Gangestad (1986) to comment that what seems to be a measure of SM may not always be, since their analyses show that the SM scales are not "direct causal link measures", which was also the conclusion reached earlier by Briggs, Cheek, and Buss (1980), and by Ellis (1988).

Snyder and Gangestad (1986) go on to claim that the measures are more sound on an empirical level, and that simply put, "it works" as long as the scales are being "evaluated and reformulated." This was what prompted the development of the cleaner and more valid 18-item version (Snyder and Gangestad, 1986).

THE VISUAL NATURE OF SELF-MONITORING

One would expect that the SM trait would emerge when the individual is allowed to use the full array of senses. However, there is evidence to suggest that it is through vision that the high SM person primarily finds his cues (Glick, DeMorest, and Hotze, 1988; Snyder, Berscheid, and Glick, 1985; Glick, 1985; Hosch and Platz, 1984). Studies using auditory stimuli have not produced significant results in determining high or low SM individuals (Santee and Maslach, 1982; Dabbs, Evans, Hopper and Purvis, 1980). 
The visual nature of SM was also shown in research on how high and low SM individuals selected occupations (Brown, White and Gerstein, 1989). High SM men were more inclined to monitor their physical appearance, and were more interested in jobs in the Enterprising domain which require very frequent visual interaction with others. Low SM individuals showed a preference for occupations in the Social domain which emphasized a background, supporting role. It is worth noting that this study reported gender differences. High SM women tended to select Artistic occupations rather than the Enterprising ones chosen by the men. The authors suggest that though the SM trait may function equally in men and women, it may be influenced by different values to lead to different outcomes.

Studies on emergent leadership and SM also point to some gender differences, and speak to the expectations that a high SM individual might have. Ellis (1988) found that when both men and women demonstrated high emergent leadership qualities, men scored higher on the SM scale than women. If leadership in a group is manifested in a high SM male, then other high SM individuals (male and female) will modify their behavior to conform with the new status quo of the situation. Low SM individuals will ignore these cues (Gangestad and Snyder, 1985b). 
The visual nature of the high SM individual was also demonstrated in studies on the ways individuals select romantic partners (Glick, DeMorest and Hotze, 1988; Snyder, Berscheid and Glick, 1985). High SM adults tended to select partners based on their physical attributes while low SM adults based their selections on desirable personality traits. Attribution theory suggests a selfimage bias (Lewicki, 1983) where people value those things that make them individual and special, and judge others based on those attributes, and assume that others who possess those attributes do the same. High SM individuals value visual cues, which in this case is physical attractiveness. Since their choice for a romantic partner is a person who is physically attractive, they assume that those who are attractive would also select an attractive partner (Berscheid, Dion, Walster and Walster, 1971; Murstein, 1972). Therefore, for high SM individuals, physical attributes come first. In a similar manner, low SM individuals, who by definition are not concerned with how others perceive them physically, tend more to consider matches in personality characteristics and interests (Glick, DeMorest and Hotze, 1988).

The results of Glick, et al (1988) expanded the findings by Berscheid, Dion, walster and Walster (1971) who demonstrated that the matching hypotheses did indeed apply. 
Berscheid, et al found that an individual tended to select a partner who was perceived to be at least as physically attractive as the individual perceived him or herself to be. In addition, the individual assumed that the partner of his choice would share in that perception of selfattractiveness and select a partner who was equally or more attractive. Perception of self-attractiveness was found to be one determinant of partner selection.

Applying the matching hypotheses to SM, the high selfmonitor, given a matching task like the one described on page 8 , would determine who was the most physically attractive person and assume that this person would desire the correspondingly most attractive member of the other gender for his or her partner. Pairs would continue to be made based on relative attractiveness, most attractive to least attractive.

\section{ADOLESCENT GROUPS}

It is interesting to note that though snyder claims that the SM trait is stable through development (snyder, 1987) and across situations (Snyder, 1974, 1979), he has not undertaken the investigation of adolescents. In fact, of the 477 references cited in Public Appearances/Private Realities, (Snyder, 1987) there was not one empirical study that involved research with this population. Also, it is 
noteworthy that of the four SM scales cited by snyder (Early Childhood Self-Monitoring Scale, Eder, 1984; the Middle Childhood Self-Monitoring Scale, Graziano, Leone, Musser and Lautenschlager, 1985; the original Self-Moniloring Scale,Snyder, 1974; and the Revised Self-Moniroring Scale, Snyder and Gangestad, 1986; as well as the Revised SelfMoniroring Scale, Lennox and Wolfe, 1984) not one claims to be designed for evaluating the trait in adolescent populations.

Snyder does offer some directions in which to pursue research with teens. He suggests that dating patterns, selection of partners, the fluctuation and changeability of peer groups, and changing environments, among many other areas, are worthy of consideration. It is in just these suggested areas that the research for this study is proposed.

\section{IMAGINARY AUDIENCES}

Because research in the SM construct does not offer a base of empirical studies for the study of adolescent groups, the imaginary audience (IA) (Elkind, 1967) may well serve this purpose. Elkind characterized this construct as one in which the adolescent is preoccupied with his own appearance and behaviors. The adolescent anticipates reactions of other people to himself based on the premise 
that others are as admiring or critical of himself as he is.

The IA construct, like the SM construct, claims a separation from the locus of control dimension (Rotter, 1966). The adolescent is more likely to be responsive to the "demand characteristics" of his environment while assuming that his responses will be the focus of attention of all those present (Elkind and Bowen, 1979). In this way, the IA construct relates directly to the concern for social appropriateness, acting, altention to social comparison information, and stability over the cross-siluaional variability of social behavior of the SM construct (Snyder, 1974). Though the SM construct implies that the high SM individual also exerts the use of this ability in particular simations, it also implies that it is the situation or the environment which triggers the high SM response. Like the child who is influenced by the IA, the high SM also assumes that the attention of the group is upon him and attempts to respond to cues in ways he believes are most appropriate. They are both most concerned with not appearing inappropriate in the eyes of the group.

There is one subtle difference, however. Elkind and Bowen (1979) state that in the IA case the individual will focus inwardly, while in the SM case the direction is outward. In the IA case, an individual may have subsequent feelings of embarrassment and may withdraw from social interaction, while the high SM individual, though also 
sensitive to the group's attention, tends to feel more involved and comfortable as attention increases. This may be a function of the individual's learned strategies for dealing with potentially embarrassing situations.

Results of studies on the IA effect show that young adolescents will be more self-conscious than children or older adolescents (Hauck, Martens and Wetzel, 1986). An interesting deviation from the SM construct is that girls tend to be more concerned with the IA than boys (Elkind and Bowen, 1979), and furthermore, the emergence of adolescence produces a disturbance in the child's self-picture, bringing on a crisis in self-consciousness:

...his picture of himself has become more shaky and unstable; his global self-esteem has declined slightly; his attitude toward several characteristics which he values highly has become less positive; and he has increasingly come to believe that parents, teachers, and peers of the same sex view him less favorably. (Simmons, Rosenberg and Rosenberg, 1973, p. 559)

Though these findings are stated in negative terms, Simmons, et al. (1973) are describing an individual who is becoming aware of the gives and takes of a peer group culture. This is one of the keys to understanding the behavior of a high SM individual.

Hudson and Gray (1986) support these findings, adding that environmental factors are also working. They found that socialization factors associated with beginning middle school heighten self-awareness and consciousness of others, and that girls are more attuned to interpersonal relations 
than boys "and thus should be more responsive to various aspects of the phenomena of adolescent egocentrism."

As school continues and age increases, the effect of the IA decreases, as well as the differences of the IA effect between genders (Enright, Lapsley and Shukla, 1979: Elkind and Bowen, 1979; Hudson and Gray, 1986). This suggests a growing-up process by which the adolescent begins to view the self more realistically. In as much as the SM construct has not been studied at the adolescent level, this may be one reason why there have been no gender differences reported.

\section{ENVIRONMENT}

The literature on both SM and the IA comments on the possible effects of the environment. Snyder (1987) hypothesizes that from the genetic standpoint, high SM individuals may be born with a "predisposition" for the trait, and that development of the trait takes place over time.

This development over time occurs, of necessity, in an environmental context. For the activities that define the high and low self-monitoring interpersonal styles can only occur in social situations. (Snyder, 1987, p.138)

Snyder and Gangestad (1986) point out that when people spend time in situations that support their own tendencies, it should be easier for these tendencies to emerge if latent. There should be situations where the high SM trait 
is more salient. However, studies attempting to find an effect of different demographic variables have not produced any significant results (Snyder and Simpson, 1984; Snyder and Monson, 1975). Snyder summarizes:

There is simply no reliable evidence that selfmonitoring is meaningfully associated with social class, economic status, regional origins, geographical movement (being high or low is not the product of frequent moves and adjustments to new surroundings or the stability of remaining in the same community from birth through adulthood), or religious affiliation. (Snyder, 1987 p.131)

and finally,

...the social circumstances and life experiences that bring out divergent self-monitoring orientations may be ones toward which people gravitate precisely because of their selfmonitoring predisposition. It is in this sense that, when it comes to self-monitoring, it is proper to say that people are first born and then made. (Snyder, 1987 p.153)

The argument is somewhat more concrete with the IA construct. The entrance of the child into early adolescence clearly shows an increase in IA behaviors (Lapsley, Milstead, Quintana, Flannery and Buss, 1986; Hudson and Gray, 1986; Simmons, Rosenberg and Rosenberg, 1973). Since this movement into early adolescence coincides with a change from elementary to middle schools, it is possible that school changes may have some effect (Elkind and Bowen, 1979).

Elkind (1967) points out the developmental aspects of the construct and its roots in Piaget's stage theories of development when the child becomes capable of operational 
thinking. It seems the emergence of the IA is due to a combination of both environmental influences as well as developmental processes, and their timing.

\section{MEASURES AND HYPOTHESES}

The main focus of this research was to assess if and how SM could be measured with adolescents. In order to come up with some ideas about what to expect from the data, since there has been no reported research on SM with adolescents, the IA construct provided a support to help develop the hypotheses and their predicted outcomes. The IA construct was very useful for this purpose, since it seems to have several important features in common with SM. Among these similarities are responsiveness to environmental cues, awareness of one's own position and feelings in social settings, and use of vision as the primary modality. Also, the IA construct gives some specific data on gender differences, while research on gender differences in SM has been inconclusive.

The 18-item SM scale (Gangestad and Snyder, 1985b, see Table I) used in this study was developed from the original 25-item SM scale (Snyder, 1974). The 25-item scale was shown to have a Kuder-Richardson 20 reliability of .70 with a test-retest reliability of $.83(d j=51, p<.001$, one month time interval). 
TABLE I

EIGHTEEN-ITEM MEASURE OF SELF MONITORING

Item number

Item

1. I find it hard to imitate the behavior of other people. (F) (.39)

2. At parties and social gatherings, I do not attempt to do or say things that others will like. (F) (.20)

3. I can only argue for ideas which I already believe. (F) $(.24)$

4. I can make impromptu speeches even on topics about which I have almost no information. (T) (.39)

5. I guess I put on a show to impress or entertain others. (T) (.48)

6. I would probably make a good actor. (T) (.59)

7. In a group of people I am rarely the center of attention. (F) (.45)

8. In different situations and with different people, I often act like very different persons. (T) (.25)

9. I am not particularly good at making other people like me. (F) (.28)

10. I am not always the person I appear to be. (T) (.22)

11. I would not change my opinions (or the way I do things) in order to please someone or to win their favor. (F) (.17)

12. I have considered being an entertainer. (T) (.41)

13. I have never been good at games like charades or improvisational acting. (F) (.49)

14. I have trouble changing my behavior to suit different people and different situations. (F) (.34)

15. At a party I let others keep the jokes and stories going. (F) (.45)

16. I feel a bit awkward in public and do not show up as well as I should. (F) (.31)

17. I can look anyone in the eye and tell a lie with a straight face (if for a right end). (T) (.30)

18. I may deceive people by being friendly when I really dislike them. (T) (.18)

Note: Keying is given by either $\mathrm{T}$ (true) or $\mathrm{F}$ (false) in parentheses following each item. High SM individuals tend to answer in the keyed direction while low SM individuals answer in the alternative direction. Item loading on the first unrotated factor is given in the second set of parentheses. (Snyder and Gangestad, 1986) 
an independent sample of 146 subjects yielded a KuderRichardson 20 reliability coefficient of .63 . Snyder then proceeded to use the 25 -item SM scale to predict how predetermined groups would score. Actors, who by the nature of their profession shared many common features of the high SM individual, were successfully predicted to score higher than an "unselected sample" of stanford University students $(t=8.27, d f=562, p<.001)$.

The 18-item scale developed by Gangestad and snyder (1985b) was the result of factor analysis and taxonomic procedures. A sample of 1918 subjects was used, yielding an approximate $40 \%-60 \%$, high - low split in selfmonitoring, where ten or more responses to items in the direction of high SM was considered high and 9 or less, low. Seven items on the original 25-item scale were rejected due to factor loadings below.11. Gangestad and snyder (1985b) state that the new measure has higher internal consistency of alpha $=.70$ as compared to .66 for the 25-item measure, making it more "factorially pure."

The first unrotated factor of the 18-item scale accounts for $62 \%$ of the total variance. The second unrotated factor was estimated to have a very low correlation $r=.03$ with the total scale scores of the 18item measure. By comparison the 25-item scale accounted for $51 \%$ of the variance on the first unrotated factor while having an estimated correlation $r=.15$ with the total 25- 
item measure on the second unrotated factor. Though the 18-item scale performed better than the 25-item scale under factor analysis, the two scales were correlated very strongly $r=.93$.

A second measure to be used in this research comes from a study by Glick, Demorest and Hotze (1988) of which this is, in part, a replication. These researchers found that high SM adults focussed on levels of physical attractiveness when assessing compatibility in couples, and low SM individuals on similarity of personality traits and interests.

subjects were asked to make up "romantic pairs" based on photographs and biographical data. This was followed by the administration of the 18-item SM scale (snyder and Gangestad, 1986). It was hypothesized that high SM individuals would make selections based on attractiveness. Though gender effects were studied, none were observed; however, main effects were significant at the $p .<.0001$ level.

The above study provides a strong measure which can be employed with adolescent populations. Since dating becomes central upon puberty and continues to be an important focus through adolescence (Simmons, Blyth, Vancleave and Bush, 1979; Gargiulo, Attie, Brooks-Gunn and Warren, 1987;Roscoe, Diana and Brooks, 1987), and into adulthood (Glick, DeMorest and Hotze, 1988), the procedure will hold the 
interest of the populations under study, and will provide a measure of control for a possible lack of interest in, or difficulty with completion of, the 18-item SM scale. This leads to the first hypothesis.

(1) The findings of Glick, et al. (1988) will be replicated using adolescent groups.

Snyder maintains that the distribution of high and low SM individuals remains stable across age and unrelated environmental factors. The IA effect, by contrast, emerges at puberty and then drops off as age increases. It has also been shown that the IA is most salient following the transition of the child from elementary school to a middle or junior high school setting, which suggests an environmental effect. In addition, behaviors observed by this author working with adolescents in alternative schools seemed more characteristic of high SM than behaviors observed in regular schools. Since this study spans both different school and living environments, as well as a range of ages, two hypotheses are proposed:

(2) As groups deviate from the "normal school" environments, the incidence of the high SM individual will increase.

(3) As age increases the incidence of high SM will decrease. 
The data in support of the IA construct suggest gender differences. It has been pointed out that girls may be more egocentric and self-conscious than boys in early adolescence, but this effect evens out over time (Elkind and Bowen, 1979). The SM construct does not identify any gender differences, yet in terms of SM, adolescents have not been studied.

(4) At younger age levels girls will have a higher incidence of SM than boys, and this difference will even out as age increases.

Hypotheses (5) and (6) were based on the matching hypotheses (Berscheid, et al., 1971). When asked who they would like to date,

(5) High SM subjects will select a physically attractive target as a projected partner, and

(6) When asked why they chose as they did, high SM will verbalize interest in the physical attractiveness of the target, while low SM subjects will express interest in a personality attribute, or share the target's area of interest. 


\title{
CHAPTER II
}

\author{
METHODS
}

\section{SUBJECTS}

One hundred sixty-one teenage subjects, 82 male and 79 female, from five school settings participated in the study. Participating were two 12 th grade social studies classes at a regular suburban high school (56 subjects), two 9 th grade social studies classes at a regular suburban junior high school (46 subjects), one alternative secondary school (grades $7-12,24$ subjects), and residents at two correctional institutions for adolescents (grades $7-12$, 35 subjects).

Since the subject areas of the classes at the regular high school and regular middle school were part of required curricula of the schools, sampling was considered to be representative of the school student bodies. At the alternative school and the correctional settings the entire student populations were involved.

A follow-up questionnaire (FUQ) was later administered in a return visit to the high school groups (45 subjects) the junior high school groups (109 subjects), and the alternative school (29 subjects). A new college group (33 students) was also surveyed. (See Table II) 
TABLE II

SUBJECT DISTRIBUTION BY SCHOOL/PROGRAM AND GRADE FOR THE EXPERIMENTAL PROCEDURE AND THE FOLLOW-UP QUESTIONNAIRE (FUQ)

Experimental Procedure

School/Program

*High School 1

*High School 2 Total High School

$\star J r$. High 1

$\star J r$. High 2

Total Jr. High

*Alternative School

Total Alternative

\section{Grade}

12

12

9

9

$7-12$

School
Number

30

26

26

20

46

24

24

20

15

Total $\frac{35}{161}$

56 $\underline{\text { Total }}$

$7-12$

$7-12$

Total Correctional School

\begin{tabular}{|c|c|c|c|}
\hline \multicolumn{4}{|c|}{ Follow-Up Questionnaire } \\
\hline School/Program & Grade & Number & Total \\
\hline $\begin{array}{l}\text { College } \\
\text { Total College }\end{array}$ & 200 level & 33 & 33 \\
\hline *High School 1 & 12 & 26 & \\
\hline *High School 2 & 12 & 19 & \\
\hline Total High School & & & 45 \\
\hline *Jr. High 1 & 9 & 52 & \\
\hline *Jr. High 2 & 9 & 57 & \\
\hline Total Jr. High & & & 109 \\
\hline *Alternative school & $7-12$ & 29 & \\
\hline Total Alternative & School & & $\frac{29}{200}$ \\
\hline & & Total & 209 \\
\hline
\end{tabular}




\section{PREPARATION OF MATERIALS}

The packet of materials used in each school setting contained three major components. The first offered the prospective subject an overview and explanation of the experimental procedure, parental permission forms and a student consent form. (See addenda.) The second component involved the evaluation of photographs (called "targets") by a group of students, and consisted of 20 pictures from which 10 were selected to be used as the visual stimuli. The third component combined the selected photographs with 10 previously prepared biographical sketches, and also included the 18-item SM questionnaire in text form, audio tapes of the 18-item SM questionnaire and a typed card with the 10 areas of interest associated with each target in the biographical sketches. (See addenda.)

\section{TARGETS}

The "targets" (photographs of young men and women) provided the visual stimuli in the couple make-up task of the experimental procedure. Target subjects were recruited from freshman and sophomore psychology classes at Portland State University. All pictures used a standard format and were head and shoulder color portraits. From the 60 photographs originally taken, individuals who looked too old or unconventional in appearance were screened out. In 
all, the photographs of 10 men and 10 women were selected to be used in the study. Target subjects were asked to sign a photo release form giving permission to use their photos. (See addenda.)

Following the procedures described in Glick, Demorest and Hotze (1988), at each school site a panel of six female and six male students were selected from volunteers taken from the classes following the initial presentation of the experimental procedure. These students were asked to rank the 20 target photographs terms of physical attractiveness ( 1 being least attractive and 10 being most attractive). The scores given by the 12 students on each target were totaled and ranked. The first, third, sixth, eighth and tenth rated male and female targets were then used. This procedure was repeated at each school since it could not be assumed that students at all schools would perceive and rank the attractiveness of the targets the same way.

\section{PERSONALITY SKETCHES}

The portraits were then combined with biographical data in the form of ratings ( 1 being low and 9 being high) on sense of humor and personaliy. In addition, an area of personal interest was given to each target. Altraciveness, humor, personality (extroversion) and personal interests were manipulated so that each male target had a corresponding female target that had 
similar ratings on the humor and personality dimensions and a compatible personal interest. Values given to these items were varied slightly by raising or lowering an item on the 1 to 9 scale so that patterns could not be readily identified. For example, a 5 might be made a 6 or a 3 made into a 2 so that the best-matched pairs were equal on one dimension and only different by one point on another (Glick, DeMorest and Hotze, 1988).

\section{EXPERIMENTAL PROCEDURES}

Subjects were interviewed individually. Materials and procedures were presented in the following sequence. First, they were shown the pictures and biographical information. The investigator then said:

These are pictures of students at a nearby school. We are trying to make up boy-girl pairs who would enjoy going out with each other. Look at the pictures and information given. I want to see how you would make up boy-girl couples that you think would be most compatible. Please tell me when you have made your five matches.

After making up the five couples, subjects were given the 18-item SM scale (Snyder and Gangestad, 1986). Since it was not certain that all subjects possessed the reading skills necessary to complete the questionnaire, the 18-item SM scale was recorded in a spoken version, and played back through earphones. Following each recorded item was a 4second pause for the subject to consider and then circle 
true (T) or false (F) on the questionnaire (see addenda). Subjects were then presented with the five portraits belonging to their opposite gender and asked with whom they would most like to have a date, and then asked why they made their choice. Next, the subjects were asked to make a self-rating ( 1 being low and 9 being high) on the three dimensions of atracilieness, humor and personaliy, and to choose from the interests presented with the targets, the one that had the most appeal to themselves.

This completed the running of the experimental session. Subjects were asked if they had any questions, which were answered. Subjects were also cautioned not to discuss the experiment with other students until school was out for the day or until all subjects had been interviewed.

\section{FOLLOW-UP QUESTIONAIRE (FUQ)}

Following the completion of the experimental procedure, preliminary results showed that at two sites, virtually all the subjects made up their couples based on personality, even though a large proportion of the subjects were shown to be high self-monitors based on their answers on the SM questionnaire. At the other two sites, the subjects performed as predicted with high SM correlating positively with couples made up on the basis of attractiveness, while low SM subjects based their selections on similarity of personality traits. 
It was suspected that there may have been some element that skewed the results. Elements suggested included the school curriculum, the school setting, attitudes towards psychological experiments in general, and some procedural consideration in this study.

Three of the four schools were revisited and students in those classes from which subjects for the original procedure had been chosen were asked to complete a six-item questionnaire. Students who had not been subjects were invited to participate in this survey as well as those who did originally participate. The jail setting was excluded because one of the units had been transferred to another facility in another town, and it was felt that the turnover among the inmates was so great that any group surveyed with the FUQ was not likely to be representative of the earlier one. The Follow-Up Questionnaire appears as Table III. Since the experiment by Glick, et al. (1988) used subjects drawn from undergraduate psychology classes, a group of college students was also surveyed in the FUQ. In all, 209 individuals were interviewed with the FUQ, including 33 college students, 45 twelfth graders, 109 ninth graders, and 29 students from the alternative school setting. (See Table II)

The FUQ was presented to each class as a group. Students were asked to complete the information on the top, indicating gender and age and whether they had participated 
TABLE III

FOLLOW-UP QUESTIONNAIRE

Experiment

Boy $\longleftarrow$ Girl

1. Did you believe that some answers would be more correct than others? Yes — No

2. Did you feel that you would be asked to reveal something personal? Yes No

3. Which of the following would have the greatest influence on how you make up couples?

Trying to figure out what the interviewers wanted.

Experiences of your friends and yourself.

Things you learned in school, (i.e., health class, social studies, P.E.)

4. Have people tried to influence you that, when choosing a date, personality is more important than looks?

Yes No

5. On a scale of 1 to 5, how free did you feel you were to answer honestly any way you wanted?

LOW $1 \ldots--^{2}---^{3}-\ldots 4 \ldots-\ldots 5$ HIGH

6. Did the interviewers give hints on what they were looking for?

Yes

No 
in the original procedure. students who had undergone the original procedure were asked to recall their feelings just prior to and during that procedure. students who had not participated were asked to recall their feelings when the original procedure was presented or, for lack of anything better, to use this experience of completing the FUQ to respond to the question items. After the FUQ was completed, the students were engaged in discussion about the purpose of the original experiment, along with some of the preliminary general results, and the purpose of the FUQ and reasoning behind the items. 


\section{CHAPTER III}

\section{RESULTS}

The Chi-square procedure (Bruning and Kintz, 1987) was used to test hypothesis (1). Data were processed using SAS statistical software. Scores on the SM scale separating students into high and low SM groups were compared with the results of the matchmaking exercise. HSM individuals were identified as scoring 10 or above on the 18-item SM scale.

The subjects made five male-female couples. Each male and female target had a rating based on attractiveness:

1 (most attractive) to 5 (least attractive). The

difference between the ratings of the male and female that made up a couple was computed, and totaled over the five couples made by each subject. Thus, if the most attractive male was matched with the third rated female, the difference would be 2 .

It was hypothesized that HSM individuals would make up couples based on attractiveness (as defined by the panels), the most attractive male being paired with the most attractive female, the second most attractive male with the second most attractive female, etc. until the fifth rated male was paired with the fifth most attractive female. The difference between the male-female ratings in each couple 
would be zero and the summed differences for all five couples would also be zero.

An overall mean of the summed differences was computed. High SM individuals were identified as having sums below the mean, while low SM individuals had sums above. Chi-square was computed between the summed differences and the SM scale was significant, $X^{2}=22.988$, $d f=1, p<.001$. This showed a strong main effect, but when displayed on a school by school basis (see table IV) only two of the schools showed significant differences; in the 9 th grade setting and in the jail there was almost no effect at all.

TABLE IV

EXPECTED VALUES VERSUS REAL VALUES ON CHI-SQUARE TEST FOR HYPOTHESIS ( 1 )

School 12th Gr. 9th Gr. Alt. Sch. Jails Total High SM and low pair differences:

\begin{tabular}{lccccc} 
Expected & 34 & 16 & 9 & 5 & 97 \\
Actual & 23.125 & 15.52 & 6.25 & 5.6 & 87.04 \\
\hline
\end{tabular}

Low SM and high pair differences:

$\begin{array}{llllll}\text { Expected } & 18 & 7 & 8 & 12 & 18\end{array}$

\begin{tabular}{llllll} 
Actual & 10.875 & 6.52 & 5.25 & 12.6 & 8.04 \\
\hline
\end{tabular}

Chi-Square Results / $p$ values / $O$ values:

$\begin{array}{llllll}X^{2} & 40.196 & 0.104 & 5.53 & .179 & 22.99 \\ p & <.001 & 0.747 & 0.019 & .673 & <.001 \\ \Phi & -.847 & -.048 & -.480 & .071 & -.077\end{array}$

Note: Phi was computed as an indication of the degree of relationship between the scores on the SM scale and the summed differences in attractiveness between the male and female targets of the five couples made up by each subject, and shows a degree of correlation between the two measures. 
Hypothesis (2) states that as groups (schools) deviate from the "normal school" environment, the incidence of high SM will increase. This was measured using the KruskalWallis ANOVA method (Ferguson and Takane, 1989). The nullhypotheses was rejected (chi-square approximation), $x^{2}=$ 9.1298, $d f=3, p=.0276$. However, rather than projecting higher self-monitoring in the alternative environments, lower self-monitoring was observed as the environments became more restrictive (see Table V). A Z-test for significant differences on independent proportions (Marascuilo and MCSweeny, 1977) was also computed to evaluate if any of the groups significantly deviated from the $40-60$, high-low split claimed by snyder to represent the distribution of self-monitoring. The 12 th grade group had $Z=3.846, p<.001$. The 9 th grade group had $Z=2.04$, $p<.041$. The jail setting produced the only group which was not significant, $Z=0$ !

\section{TABLE $V$}

DISTRIBUTION OF HIGH VERSUS LOW SELF-MONITORS AT THE DIFFERENT SETTINGS

\begin{tabular}{lccccc} 
School & $\begin{array}{c}12 \text { th Gr. } \\
16-19\end{array}$ & $\begin{array}{l}9 \text { th Gr. } \\
13-15\end{array}$ & $\begin{array}{c}\text { Alt. Sch. } \\
12-17\end{array}$ & $\begin{array}{c}\text { Jails } \\
12-19\end{array}$ & Totals \\
Ages & $16 \%$ & & & \\
& & $74 \%$ & $63 \%$ & $40 \%$ & $62 \%$ \\
$\%$ High & $66 \%$ & $26 \%$ & $37 \%$ & $60 \%$ & $38 \%$ \\
\hline Low & $34 \%$ & 46 & 24 & 35 & 161
\end{tabular}


To test hypothesis (3) which stated that as age increases, high SM will decrease, a spearman Rank-order Correlation (Rho) was computed (Bruning and Kintz, 1987) yielding $R / \omega=-0.134, p=.0905$, which, though not significant at the .05 level, does suggest a trend. Hypothesis (3) was therefore marginally supported.

Hypothesis (4) states that girls will display a higher incidence of high SM than boys at younger ages, but that this will even out over time. This was measured by the Two-Treatment Hodges-Lehmann Test for aligned observations (Marascuilo and McSweeney, 1977) yielding an overall $Z=$ 1.34, $p=.09$. This also supports evidence of a trend. An overall test of gender vs. SM using a Pearson correlation Coefficient yielded no significant result, $R$ ho $=-.063$, $p=.428$.

Chi-square was computed to test hypothesis (5). High and low SM students were evaluated on their choice of whom they would like a date with and how attractive the target was. A target that was rated 1,2 or 3 was considered an atractive choice. Results were not significant $x^{2}=.393, d f=$ $1, p=.531$, thus not supporting the hypothesis that HSM individuals would select dates for themselves based on attractiveness.

Likewise, on hypothesis (6), where answers were coded for referrals to the target's atraciveness or for other reasons 
for the selection, HSM students did not state that their choices for dates were made on the basis of attractiveness, $x^{2}=1.791, d f=1, p=.181$.

Spearman Rank-order Correlations (Rho) (Bruning and Kintz, 1987), were computed to assess reliability of panel selections of most to least attractive male and female targets between the four sites. Decisions made by all the panels were highly correlated, with only the regular high school and jails not significant at $p=.05$ on the male targets (see Table VI). However, on male targets the jails were extremely highly correlated with the alternative school, whose populations had been hypothesized to be similar. The overall results of this procedure shows that student panels in all the test sites seemed to rate targets, in terms of their attractiveness, the same way.

\section{FOLLOW-UP QUESTIONAIRE}

The Follow-Up Questionnaire was developed to help explain why even though procedures were consistent in all settings, the results on hypothesis (1) were not. The 12 th grade and alternative school results were significant while the 9 th grade and jail results were virtually random. A series of hypotheses were developed to answer these questions: (A) Was self-monitoring unmeasurable with some of the groups? (B) Were the hypotheses of the experiment given away by the procedure, the interviewer, or in the 
TABLE VI

RELIABILITY OF PANEL ATTRACTIVENESS RATINGS BETWEEN SCHOOLS

FEMALE

$\begin{array}{lccccc} & \text { HS } & \text { JHS } & \text { Alt Sch } & \text { Jails } \\ \text { HS } & -- & .721 \text { (d) } & .8056 \text { (e) } & .8818 \text { (f) } \\ \text { JHS } & & -- & .8908 \text { (f) } & .8876 \text { (f) } \\ \text { Alt Sch } & & & -- & & .9724 \text { (f) } \\ \text { Jails } & & & -- & & \end{array}$

MALE

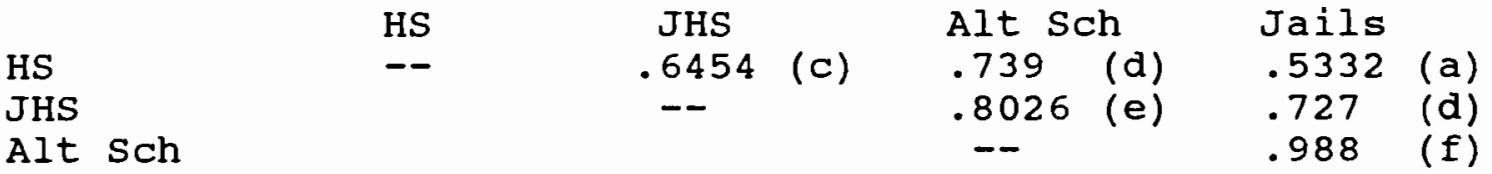

Spearman Rank-order Correlation (Rho)

Significance levels (a) $<.10 \quad d f=8$ one tailed test

(b) $<.05$

(c) $<.025$

(d) $<.01$

(e) $<.005$

(f) $<.0005$ 
initial presentation of the project to the groups? (C) Was there a higher level of trust in some of the groups? Was there an institution/school/education effect (SE) in that students had been instructed that, when dating, an individual should take attributes other than looks into account, and regarded this experiment as a test to see if the individual knew the right answer? or (E) Was there some combination of effects that led to an overall school influence or experimenter influence?

Question 5 on the FUQ directly addressed the issue of whether the subject felt inhibited or restricted in any way in giving a response. Age, school and whether the individual participated in the original procedure were assessed in this item. A Kruskal-Wallis test for age yielded $x^{2}=22.944, d=11, p=.018$ indicating that as age increased so did reported levels of trust.

A Kruskal-Wallis Test also showed a school effect, yielding $x^{2}=16.302, d f=3, p=.001$ (see Table 7).

Follow-up Mann Whitney U-Tests were calculated for all pairs of schools to find which school groups were significantly different. The 9 th grade was significantly different from the 12th grade, $z=2.821, p=.0048$ and from the college group, $z=3.598, p=.0003$. The 9 th grade was almost significantly different than the alternative school $z=1.783, p=.0745$. 
An evaluation of whether those individuals who participated in the procedure felt more or less free to answer honestly was not significant. Students were asked as they began to complete the FUQ to indicate in the experiment space whether they had participated in the initial procedure. This response was compared with reposes on Question (5) using the chi-square procedure. This seems to indicate that while there were differences between schools, attitudes on feelings of inhibition or feeling restricted to respond within schools remained constant.

\section{TABLE VII}

\section{SCHOOL SETTINGS VERSUS LEVELS OF TRUST}

\begin{tabular}{|c|c|c|c|c|c|c|}
\hline School & N & $\begin{array}{l}\text { Q5 Mean } \\
\text { Rating }\end{array}$ & $\begin{array}{l}\text { Sum of } \\
\text { Scores }\end{array}$ & $\begin{array}{l}\text { Expected } \\
\text { Under HO }\end{array}$ & $\begin{array}{l}\text { Std Dev } \\
\text { Under HO }\end{array}$ & $\begin{array}{l}\text { Mean } \\
\text { Score }\end{array}$ \\
\hline Sch & 29 & 4.034 & 3212.5 & 3045 & 284.274 & 110. \\
\hline JHS & 109 & 3.775 & 9164.5 & 10710 & 411.049 & 89.8 \\
\hline HS & 45 & 4.244 & 5243.5 & 4725 & 338.01 & 116.5 \\
\hline College & 33 & 4.454 & 4324.5 & 3465 & 299.858 & 131.0 \\
\hline
\end{tabular}

Kruskal-Wallis Test (Chi-square Approximation) Chi-Square $=16.302, d f=3$, Prob $>$ CHISQ $=0.001$

Question 1 was designed to assess whether a subject entered into the experiment with a preconceived idea that the experiment was a test or a problem to be solved, and there were therefore right and wrong answers to be given. In all, $67.59 \%$ of all those surveyed responded that this was how they felt. A chi-square was computed comparing 
those who participated in the original experiment with those who did not. It was not significant: $x^{2}=.729$, $d f=1, p=.393$. When the 12th graders were compared with the 9th graders on Question 1, a Chi-square was almost significant, $x^{2}=3.646, d f=1, p=.056$. This showed a strong trend for the 9 th graders to feel that answers must be right or wrong, whereas the 12 th graders showed a trend towards feeling that the questions were for the individual to respond to in the way he or she felt best.

Question 2 did not yield a significant effect between the 9 th grade and the 12 th grade groups. However, when comparing those who did and did not participate in the original procedure, the result was significant: $X^{2}=7.79$, $d f=1, p=.005$. This result showed that those who participated in the experiment had a lower level of anxiety about the nature of the questions than those who did not. Question 4 did not yield a significant result between the 9 th and 12 th grade groups, nor between those who participated in the original experiment and those who did not. It is interesting to note that an overwhelming $69.5 \%$ indicated that others had tried to influence them to make dating choices based on personality rather than looks. In a discussion following the completion of the FUQ, an entire class (approximately 60 students) of 9 th graders agreed that they had discussions of how to choose a date (in 
school classes, with friends, at church, and with family), that these discussions may have influenced their selections in the original procedure, and that these discussions emphasized the importance of considering personality over looks.

Question 6 was significant between the 9 th and 12 th graders, $X^{2}=6.85, d f=1, p=.009$. The 9 th graders felt that the experimenters gave hints to a higher degree than the 12th graders. Those who did not participate in the original procedure were instructed to respond based on the original class presentation about the experiment, or, if they missed that presentation, based on how they felt about the FUQ. The resulting $\mathrm{Chi}$ square was significant, $X^{2}=$ 12.037, $d f=1, p=.001$, indicating that those who did not participate felt they could read hints better than those who did.

It seemed possible that an overall school influence (SE) might also be responsible for the difference between the 9 th and the 12th graders. The SE was defined by combining responses to Questions 1, 3, and 4. The students believed : (1) since this was part of a school sponsored activity, and since the nature of the experiment reflected topics of discussion presented in health class and with other significant people, there were correct and incorrect answers; (2) that they were most influenced in their responses by friends and school courses; and (3) that there 
was substantial pressure by others on them to make date choices based on personality over just looks. There was no evidence of an overall school influence: $X^{2}=.284, d f=1$, $p=.594$

An experiment influence was also looked at to see if the two regular school settings differed in the way the students perceived what was occurring in the experiment. Given that procedures for presenting and conducting the procedures were consistent, perceptions about the nature and relative safety of participation should also remain consistent between groups. On the FUQ, Questions 2, 3, 5 and 6 were combined. Safety was reflected in Questions 2 and 5, which referred to whether the subject feared having to reveal something personal and whether he or she felt unable to answer honestly. (Note, in order to be rated as showing an experiment influence, Question 5 needed to be scored to below the mean.) Questions 3 and 6 reflected whether the subject felt that he or she was able to "read" the experiment and give the answers the researcher was looking for. A Chi-square was computed comparing the 9 th and 12 th graders against scoring high or low on this index, yielding a significant $x^{2}=5.35, d f=1, p=.021$. The 9 th graders demonstrated a clear tendency to react to the effects of participating in this experiment by making conservative decisions. These decisions seemed to be based on cues from classes taken, peer relationships, and 
interactions with other significant people in their lives. If this were the case, the 9 th graders would seem to be responding in a high SM mode, but one that was different from that anticipated by the original experiment. 
CHAPTER IV

DISCUSSION

The overall significance of hypothesis (1) was important to the analyses of all the other measures in that it supported Snyder's self-monitoring construct (SM) and showed that the SM worked and was measurable in adolescent groups. There was some concern that only two of the four groups studied showed significant results. This led to the development of the follow-up study and questionnaire (FUQ).

\section{SITUATIONAL AND AGE EFFECTS ON RESPONDENTS}

The questions in the FUQ attempted to resolve the issue of the 9 th grade response to the pair-making task (which was almost unanimously based on personality) from two perspectives. The first of these, safety, addressed how comfortable the subject felt with the procedures of the project, and how much trust the subject felt for the interviewer. The second perspective involved whether there was a school influence, either through the curriculum, or through interactions with the teachers and peers.

Rather than ask why the procedure did not work with the 9 th graders, the success of the 12 th graders and 
students in the alternative school was evaluated. A review of the curriculum of the 12 th grade classes showed that Psychology was the major topic. Though experimental procedures were not explicitly discussed in class, the students had completed several questionnaires that illustrated psychological constructs that were being studied. During the presentation of the experiment to the students, both the students and the teacher expressed an active interest in being part of a study. They looked upon the discussion about protection of the subject's anonymity and the required procedures for getting parental permission and informed consent as necessary but tedious, and clearly demonstrated a desire to begin as soon as possible. In the 12 th grade group, out of 58 who were originally approached, 56 (or 97\%) agreed to participate.

In the alternative school setting, the experimenter was a known entity who had worked in the school part-time over the previous four years. Though the project was presented to the entire student body for their consideration, (only 27 of 34 students were in attendance that day), there were numerous additional opportunities for the students to ask questions on a one-to-one basis about how the experiment was going to be conducted. The students seemed particularly interested in how the information was going to be used, and how anonymous they would be. 
Since the attendance of many students was inconsistent, data were collected on more than one occasion, and some students who may have been holding back were able to observe that no harm came to those who did participate. In all, 26 students agreed to participate. Two of these were absent on the days data were being taken, giving us a $77 \%$ rate of participation for the whole school. Unfortunately, there was a confound between age and school since the 9 th and 12 th graders attended schools in different districts. It is impossible to sort out whether differences found between these groups were due to age, grade, or environment. Yet, the 12th grade and alternative school groups are easily contrasted with the 9 th graders. There was much concern among the 9 th grade students during the presentation of the project about exactly what information would be collected and who would have access to it. It was necessary to explain in great detail how the responses were to be kept anonymous, and exactly how the procedures were designed to separate responses from individuals so that identification of who made which responses would be impossible. Several questions about needing to take permission slips home, which demonstrated an anxiety about sharing the project with parents, were raised. In all, about 48 of 109 (44\%) of the 9 th grade students present chose to follow through and participate in the experiment. 
It was concluded from this anecdotal information that the 12 th graders were quite relaxed from the beginning regarding the procedures. They seemed self-assured, and demonstrated by their discussion an understanding that their privacy and dignity would not be compromised. The alternative school students also developed over time a high degree of feelings of safey, due to easy access to the experimenter, and by having a period of time in which they could observe others who had already participated, thus relieving their anxieties.

Another area of concern was that of the method itself, and the development of the following question: was there something inconsistent in the procedures that caused the 9 th graders and the 12 th graders to answer differently? Throughout the course of all procedures completed in all locations the interviewers used the same script; all interviews were conducted individually; the presentation of the project was the same for each group; any questions students had about specifics on the looks versus personality aspects of the experiment and the nature of high and low SM individuals were deferred to a debriefing following the completion of the procedure and to a followup meeting with the whole class to share some of the results. In addition, there was no turnover in the interviewing team. It was concluded that procedural 
efforts remained adequately constant and did not offer a reasonable explanation for the results.

Finally, was there an institution/school/education effect? The

focus of this question was the possible activities the students were involved in prior to or at the same time as data were being collected. There may have been a certain message or curriculum the students were "hearing" as part of the school ambiance. There also may have been expectations on the part of the students that this was a continuation of classroom activities and required a specific correct response.

The IA construct was also supported in part by Question (6) on the FUQ. The 9 th graders perceived the interviewers as giving hints as to how to respond to questions. In other words, since there was a lower degree of perceived freedom to answer the way one felt, and since there was a belief that there were right and wrong answers, it follows that the subject would then be looking for "hints" on how to respond. The procedure, by design, was developed so that the subject would respond by indicating a choice based on either attractiveness or personality. These "hints" became "obvious" to the sensitive 9 th grade subject who had recently become sensitive to this issue due to recent instruction and interaction with peers and significant others on this topic. 
Another aspect of this effect lies within the concept of self-monitoring (SM). High SM individuals are constantly on the look-out for exactly this type of situation. They are concerned with solving problems in the most socially acceptable and appropriate manner as dictated by the demand character of the environment. In terms of this experiment, high SM individuals are concerned about finding "hints". They try to read the situation and the intentions of others in it. Thus again, where the problem posed is one with "right" or "wrong" answers, the high SM subject will look for hints on what the experimenter is looking for as part of the solution (Snyder, 1974).

Upon reviewing the results with the 9 th grade teachers, it was discovered that many of the students had just completed a unit in Health class on dating, and the subject of "how to choose a date" had been one of the topics. Also following the completion of the FUQ, the students in one of the two 9 th grade classes were unanimous in stating that pressure was placed upon them to "think" about interpersonal romantic relationships in terms other than looks, suggesting that such themes are likely to be discussed in the school experience of 9 th graders. This completes the circle and brings the argument back to the possibility of "right" and "wrong" answers, and of the procedure being perceived by the 9 th graders as a test to see what they had learned. 
To summarize, high SM students saw the matching procedure as a test, and made matches based on personality. Low SM students may not have seen the procedure as a "test", but even if they had not and had taken the procedure at face value, the response would still have been the same: a match based on personality. The 12th graders, not being as concerned with these issues, responded differently. These results represented more variability between subjects and also a significant difference between those who scored low and high on the SM scale.

\section{EXPERIMENT EFFECT AND SCHOOL EFFECT}

By combining items on the FUQ, an attempt was made to sort out a possible experiment effect from the school effect. The experiment effect was defined by asking what, if any, effect did participation in the experiment have on the responses given by the subject. This was also defined by combining the responses of questions (2), (3), (5) and (6). If the subject responded that there was a concern about revealing something personal, that he/she did not feel free to answer openly, that there were hints to be found and that he/she was trying to figure out what the experimenter was looking for, then an experiment effect was being demonstrated.

The school effect was made up of Questions (1), (3), and (4). It naturally contained the questions regarding 
"right" and "wrong" answers, things learned in school, experiences of friends and self, and influence others may have had on the subject.

It is interesting that only the experiment effect was significant between settings, while the scores on the school effect remained high with both the 9 th and 12 th graders indicating an interaction effect between grade and procedure. One interpretation is that even though both groups were concerned about issues encapsuled in the school effect, the 12th graders were more mature and felt able to respond to the experimental procedure trusting that their anonymity would be preserved, and thus not risking embarrassment or exposure. This allowed the 12th graders to respond without regard to what they might have perceived as the experimenter's intentions and to do their best to give their individual and personal responses. The main concern of the 9 th graders was being asked to reveal something personal and they did not want to be embarrassed. They were therefore inclined to look for clues and hints in the presentation of the experiment and its material, and, as in solving a puzzle, try to come up with "the solution". Another possibility is that the 9 th graders were not adequately prepared to participate. They may have needed more assurances than the 12 th graders did that it was their honest feelings and perceptions and opinions that mattered, that there was no deception contained in the procedure, and 
that no information given would come back to have an influence on them. The rigid requirements of presenting the procedures in the same way to all groups prevented the 9th grade students from developing an attitude that would allow them to respond freely. It is interesting to note that though the experiment was presented in the same way to the students in the alternative school, there were other elements that allowed the students to become more comfortable with the procedures after the presentation. For example, the 12 th graders already had some experience with (and thus some desensitization to) psychological questionnaires and surveys, and the alternative school students had already known the experimenter for a period of time.

This all leads to one final thought on the difficulty of doing research with adolescent groups. Though the 9 th graders were extremely interested in the subject of dating, they may not have been sure enough of their own feelings to feel competent to give uninhibited answers. In the discussions following the administration of the FUQ with the 9 th graders, it was evident that the subject of dating was an important issue. As the discussions continued it became easier for the students to discuss their personal positions. This was also true when reviewing the procedures of the experiment. At first the students were very cautious in stating their interpretation of what they 
thought was going on with the experiment until some ground rules for discussion were established. They were then willing to share not only important events such as the curriculum in health class, but also to discuss critically the procedure itself, and those pressures and influences alluded to in the FUQ.

It may be interesting to future investigators in SM to correlate high and low SM with deciding to participate in an experiment. It may also be interesting to investigate the relationship of high and low self-monitors to school and experiment effects.

\section{THE EFFECTS OF SELF-MONITORING}

In view of the results of the FUQ and hypothesis it would be appropriate to conclude that snyder's construct was both successful and unsuccessful in predicting the behavior or the adolescents in this study. There was an overall SM effect; however not all subjects behaved as predicted.

Hypotheses (2) speaks to a continuum of the distribution of high and low self-monitors across our four environments. Hypothesis (3) also implies a continuum, but based on age. Though there were marginal trends to indicate that HSM was greatest at the beginning of adolescence and decreased as age increased, the results certainly suggest environmental differences that could be 
attributed to maturity. In any case, the levels of HSM at both the 9 th and 12 th grade levels, as well as at the alternative school were well above the 40-60, high-low split which snyder claimed to be constant across all ages and environments.

The hypothesis that students in alternative or restricted environments would tend to be more high SM was not borne out by the data. It is interesting to note that as the project was presented to professionals in the field (i.e., the directing supervisors and staffs of the jail settings), their consensus predicted correctly that their populations would be predominantly low SM. It is possible that in this investigator's experience, he has worked only with those students who are making positive changes for themselves, and thus is seeing the students in a high SM perspective. This perspective might include helping the student to see his or her personal situation in terms of possibilities rather than liabilities, and how to take advantage of what is offered and available to him. Being shown the high SM side of the student, the investigator developed his hypotheses from that perspective.

Another explanation for the distribution of SM in incarcerated or alternative school groups is that actually there is no difference between this group and any other group of the same age and maturity level. However, the process of entering restrictive/remedial environments 
screens out high SM individuals, since they are better able to perceive opportunities to escape incarceration, and are inclined to take advantage of them.

For example, a youth that has been apprehended for a violation may first be screened by a caseworker at Juvenile Detention Hall. This caseworker may present options for remediation, drug and alcohol treatment, foster homes, alternative pleas and their possible outcomes with judge, as well as jail time. Prior to trial, the attorneys (both prosecuting and defense) may attempt out-of-court settlement or other arrangements with the judge. Finally, in court, the judge may also present the youth with alternatives to incarceration.

current trends in oregon indicate a system that is inconsistent in its corrections programs. July, 1990 figures show that there were 518 juveniles in "close custody" (incarcerated), out of a total of 1201 juveniles in the Juvenile correction system (State of oregon, 1990). Juvenile arrests, however, for the year of 1988 were 27,918 (State of Oregon, 1988). (No arrest figures were available for 1990.) These three figures illustrate that very few arrested juveniles actually see any jail time, or are even involved with the Juvenile Justice system.

The level of intervention by the Juvenile Justice System is determined by the judge who hears the complaint. There is no coordinated system for delivering services on a 
district-by-district, city-by-city, or county-by-county basis. Incarceration is often based on the whim of the judge, or on the availability of jail space at the local or state level (Oregon Youth Coordinating Council, 1989). Judges, especially on first offenses, are inclined to seek out community programs, including counseling, half-way houses, alternative schools (such as the one which participated in this study), foster care, group homes, private inpatient and outpatient mental health programs, and youth service centers as diversions and alternatives to giving jail time, or even to entering the juvenile into the system (Oregon Law Enforcement Directory, 1985; United Way of the Columbia-Willamette, 1988 and 1989). In these contacts with caseworkers, attorneys, judges, etc., the high self-monitor's ability to present a good image (or even to be conscious of the image he is presenting) will give him an advantage in obtaining the least restrictive outcome.

Self-monitoring may also be affected by the environment itself. Snyder (1987) mentions that HSM are "first born, then made by their environments" (p. 153). In the alternative school, activities are very structured and the rules governing behavior are strictly enforced. Students who take advantage of or forget the rules are asked to leave (take time-out) and to return when they are more in control, or perhaps with a parent to discuss 
whether the student will continue at the school or not. The student must be cognizant of his or her inner states in order to maintain an appropriate level of behavior. In addition, problems are solved using an introspective model in which the counselor attempts to get the student to see problems as "barriers" that can be overcome by understanding what they are and by resolving them with a plan. This again brings the student face to face with him/herself. Focussing on inner states was one of the indicators of low SM.

In the jail environment, the inmates must also be very aware of and in control of their inner states and feelings. An inopportune outburst may have dire consequences leading to solitary confinement, increased time to be served, or a restriction of privileges earned. In addition, the prison population is not homogenous. The only thing these children have in common is that they ran afoul of the legal system and got caught. In one of the two jail settings, inmates were only held from 5 to 21 days before being transferred to another facility to serve the rest of their terms, while at the other site, an inmate may be in residence for over a year.

Given the nature of prison and the barriers to forming long-term relationships, along with aspects of the treatment process which emphasize making decisions that are thought out, rather than impulsive, the inmates may be 
responding to the SM scale in a low SM mode as reflected by a cautious, withdrawn response pattern. The process in the jails is to some extent a continuation of the process used to work with students in the alternative school.

It would be interesting to compare individual results inside and outside the institution. This might be done by following inmates as they move outside the systems through half-way houses, foster homes, reunion with their natural families, and eventually independent living.

A third explanation for the incidence of low SM in the jails was offered by the director of one of the institutions visited. He said that the difference between the inmates in his setting and the students in the alternative school was that the inmates got caught. This analysis might also be applied to the students at the alternative school, in that they were not able to pick up cues for successful interaction in a regular school. The implications here are that since high SM individuals are more vigilant of their environments, they will be able to perceive when the risk of a negative consequence of an inappropriate action is too high, and will wait for a more opportune time. Another consideration is that high SM students may have a higher need for openly demonstrating success, and therefore will find a way to meet, at the very least, the minimal expectations of the regular school. As with the Juvenile Justice System, the schools will give 
students who get into trouble several chances, each one bringing with it a higher level of support and structure. With today's limited budgets, cutbacks in state spending, and increased pressure on the alternative schools and Juvenile Justice System to provide services to an extremely large and needy population, it becomes increasingly imperative that we use our few resources wisely. The very reason a child is placed in a special setting is because a need for special intervention was demonstrated. Therapy must match both the needs and the personality of the person (Shaw, 1981). Snyder (1987, p. 119) offers that behavior-oriented therapy might be best suited to high SM individuals, while a nurturing and supportive approach provided by a non-directive therapist focussing on underlying thoughts, feelings and motives may be most appropriate for low self-monitors. a further implication is that high SM inmates could best work in small groups, while low SM inmates would need lots of oneon-one.

The prisons (and the alternative school) work on a behavior model. The feedback of counselors and the documentation of positive behaviors of the inmate may result in "good-time" and early release to a less restrictive program. This serves the needs of the high self-monitors. However, with low self-monitors individual counseling may be the only way to "connect" and to get 
through to the inmate. Failing in this, the inmate is released at the end of the jail term and is more likely to be incarcerated again for another offense. Not only does this reflect the failure of the system to meet the needs of the individual, but also fills the institution with individuals whose needs are not being met by the programs in place. An interesting question for a future study would be to compare levels of SM between first time and repeat offenders.

Up to this point, the discussion has centered on hypothesis (1) on why the results were not consistent across all the environments, and hypothesis (2) on how and why the distribution of SM could vary to such a large degree between the environments and away from snyder's contention that as a class variable the proportions of high and low SM would remain constant.

It was also shown in the results on hypothesis (3) that age difference was not significant at the $p=.05$ level, which makes the environmental differences shown by the results of hypothesis (2) that much more striking. Hypothesis (4) addressed possible gender effects which were indicated by the IA construct, but not by snyder. In a way, both were correct. There certainly was no overall gender effect; however, when comparing gender with age, there was a trend. A larger, better prepared sample at the 9 th grade level may have led to a significant result. 
It was a bit of a surprise that hypotheses (5) and (6) were not significant. The results may derive from many of the same reasons as were given for the results of tests of hypothesis (1). This time, however, the activity of making a date choice was being applied to subjects personally, and the effects described as caution, trust, school, experimenter, and safety came to bear on the subject in a real way. In addition, once the process of making up pairs based on personality and interests was established, the application of this process to the self was simply a continuation.

Another possible explanation is that the targets were from a college setting, and, with the exception of the 12 th graders, the subjects may not have been able to identify readily with the people in the pictures. This left the subjects with only interests and personality ratings to make their choices. It is also worth noting that in many interviews, the interviewers felt that the subjects were focussing on the pictures while giving reasons associated with other measures. This indicated, at the very least, that the pictures served as a way to identify the individual to whom the subject was attracted, even if looks were not being used as the reason for his or her selection. When asking for responses to test hypothesis (6), the subjects almost never cited looks as their reason for selecting a date. However, when the interviewers became 
aware that the subjects were looking at the pictures while stating personality or interest as their first choice, the subject was then asked if there was more than one reason. Finally, as a last resort, they were asked if looks had anything to do with their decisions. Even with this overt probing, subjects were very reluctant to reveal a preference based on attractiveness (even as a second or third choice supporting their main reason). The question why adolescents may be so reluctant to admit an attraction based on looks may be of interest for future study.

To conclude: the main purpose of this experiment was to evaluate the effectiveness of measuring SM with adolescents. The difficulties experienced when working with the 9 th graders give some hint as to why this may not have been tried before. The overall significance of the main effect, gives some indication that the SM construct is operational with this population. The predicted higher levels of HSM in younger adolescents was shown to be supported by the data, but it was a surprise to find the proportions of HSM so much higher than snyder (1987) contends. Environmental factors seem to have a major effect on the distribution of SM, which again disagrees with snyder's contention that, as a class variable, SM should transcend environmental boundaries and remain relatively constant. 
The SM scale can be a useful prediction tool, along with other instruments, to evaluate an individual's style of interaction with his or her environment. This may have important implications for adolescents in structured settings such as school or jail. Since levels of SM may be a product of the environment, it would be interesting to attempt to correlate changes in perceptions in self-esteem with scores on the SM scale.

There seems to be some validity with the SM construct as applied to adolescent groups. Increased study is needed to demonstrate a reliability that would have practical application in a service delivery model. 


\section{REFERENCES}

Berscheid, E., Dion, K., Walster, E. and Walster, W.

(1971). Physical attractiveness and dating choice:

A test of the matching hypothesis. Journal of

Experimental Social Psychology, 7, 173-189.

Briggs, S. R., Cheek, J. M., and Buss, A. H. (1980). An analysis of the Self-Monitoring Scale. Journal of Personality and Social Psychology, 4 , 679-686.

Bronfenbrenner, U. (1986). Alienation: And the four worlds of childhood. Phi Delta Kappa, February, 1986, $430-436$.

Brown, M. T., White, M. J., and Gerstein, L. M. (1989). Self-monitoring processes and Holland Vocational Preferences among college students. Journal of counseling Psychology, 35, 183-188.

Brown, R. (1988). The reality of groups. In Group Processes: Dynamics Within and Between Groups. Oxford: Blackwell, 3-18.

Bruning, J. L. and Kintz, B. L. (1987). Computational Handbook of Statistics. Glenview: Scott, Foresman and company.

Bureau of Labor statistics (1985). Current population survey (March supplement). Washington, DC: U. S. Department of Labor.

Connell, J. P., Deci, E. L., Ryan, R. M., and Grolnick, W. S.(1989). Research on students at risk: Identification, treatment, and prevention.

Unpublished manuscript, Rochester, NY: University of Rochester.

Dabbs, J. M., Evans, M. S., Hopper, C. H. and Purvis, J. A. (1980). Self-Monitors in conversation: What do they monitor? Journal of Personality and Social Psychology, 39, 278-284. 
Eder, R. (1984). Assessing Self-Monitoring in early childhood: A 25-item measure. Unpublished research, University of Minnesota and Southern Methodist University. In Snyder, M. (1987) public Appearances/Private Realities, New York: W. H. Freeman, 144-145.

Elkind, D. (1967). Egocentrism in adolescence. Child Development, 38, 1025-1034.

Elkind, D. and Bowen, R. (1979). Imaginary audience behavior in children and adolescents. Developmental Psychology, 15, 38-44.

Ellis, R. J. (1988). Self-Monitoring and leadership emergence in groups. Personality and Social Psychology Bulletin, 14, 687-965.

Enright, R. D., Lapsley, D. K., and Shukla, D. G. (1979). Adolescent egocentrism in early and late adolescence. Adolescence, 14, 687-965.

Ferguson, G. A. and Takane, Y. (1989). Statistical Analysis in Psychology and Education, New York: McGraw Hill, pp. 441-443.

Furman, W. (1989). The development of children's social networks. In D. Belle (Ed.) Children's Social Networks and Social Supports, New York: Wiley.

Gangestad, S. and Snyder, M. (1985a). On the nature of self-monitoring: An examination in latent causal structure. Review of Personality and Social Psychology, $\underline{6}, 65-85$.

Gangestad, S. and Snyder, M. (1985b). "To carve nature at its joints"; On the existence of discrete classes in personality. Psychological Review, 92, 317-349.

Gargiulo, J., Attie, I., Brooks-Gunn, J., and Warren, M. P. (1987). Girls dating behavior as a function of social context and maturation. Developmental Psychology, 23, $730-737$.

Glick, P. (1985). Orientations towards relationships: Choosing a situation in which to begin a relationship. Journal of Experimental Social Psychology, 21, $544-562$. 
Glick, P., DeMorest, J. A. and Hotze, C. A. (1988). Self-Monitoring and beliefs about partner compatibility in romantic relationships. Personality and Psychology Bulletin, 14, 485-494.

Graziano, W. G., Leone, C., Musser, L. M., and Lautenschlager, G. L. (1985). Self-Monitoring in children: A different approach to development. Unpublished manuscript, University of Georgia. In $M$. Snyder (1987), Public Appearances/Private Realities, New York: W. H. Freeman, 146-147.

Hauck, W. E., Martens, M. and Wetzel, M. (1986). Shyness, group dependence and self-concept: Attributes of the Imaginary Audience. Adolescence, 21, 529-534.

Hormuth, S. E., (1984). Transitions and commitments to roles and self-concept change: Relocation as a paradigm. In V. L. Allen and E. Van de Vliert (Eds.), Role transitions: Explorations and explanations.

New York: Plenum.

Hosch, H. M. and Platz, S. J. (1984). Self-Monitoring and eyewitness accuracy. Personality and social Psychology Bulletin, 10, 289-292.

Hudson, L. M. and Gray, W. M. (1986). Formal operations, the imaginary audience and the personal fable. Adolescence, 21, 751-765.

Lapsley, D. K., Milstead, M., Quintana, S. M., Flannery, D. and Buss, R. R. (1986). Adolescent egocentrism and formal operations: Tests of a theoretical assumption. Developmental Psychology, 22, 800-807.

Lennox, R. and Wolfe, R. (1984). Revision of the Self-Monitoring scale. Journal of Personality and Social Psychology, 46, 1349-1364.

Lewicki, P. (1983). Self image bias in person perception. Journal of Personality and Social Psychology, 45, 384-393.

Marascuilo, L. A. and McSweeney, M. A. (1977). Nonparametric and Distribution Free Methods for the Social Sciences. Monterey: Wadsworth, 296-400.

Murstein, B. I. (1972). Physical attractiveness and marital choice. Journal of Personality and Social Psychology, 22, 8-12. 
Oregon Youth Coordination Council, (1989). oregon Model Youth Programs, Oregon Department of Education.

Oregon Law Enforcement Directory (1985). Beaverton, oregon. pp. 1-41.

Orne, M. T. (1962). On the social psychology of the psychological experiment: With particular reference to demand characteristics and their implications. American Psychologist, 17, 776-783.

Roscoe, B., Diana, M. S. and Brooks, II, R. H. (1987). Early, middle and late adolescents views on dating and factors influencing partner selection. Adolescence, $\underline{22}, 59-68$.

Rotter J. B. (1966) Generalized expectancies for internal versus external control of reinforcement'

Psychological Monographs, 80 (Whole No. 609).

Santee, R. T. and Maslach, C. (1982). To agree or not to agree: Personality dissent amid social pressure to conform. Journal of Personality and Social Psychology, 4ㄴ, 690-700.

Schachter, S. and Singer, J. (1962). Cognitive, social, and physiological determinants of emotional state. Psychological Review, 69, 379-399.

Shaw, B. F. (1981). Matching treatment patients in an inpatient setting. In L. P. Rehm (Ed.), Behavior Therapy for Depression. New York: Academic Press.

Skinner, E. A., and Kindermann, T. A. (1990). Motivation in school: Impact of teachers and peers. Unpublished manuscript.

Simmons, R. G., Blyth, D. A., Vancleave, E. F., and Bush, D. M. (1979). Entry into early adolescence: The impact of school structure, puberty, and early dating on self-esteem. American Sociological Review, 44, 948-967.

Simmons, R. G., Rosenberg, F., and Rosenberg, M. (1973). Disturbance in the self-image at adolescence. American Sociological Review, 38 , 552-568.

snyder, M. (1974). The self-monitoring of expressive behavior. Journal of Personality and Social Psychology, 48, 970-998. 
Snyder, M. (1979). Self-monitoring processes. In L. Berkowitz (Ed.) Advances in Experimental social Psychology, 12. New York: Academic Press.

Snyder, M. (1987) . Public Appearances, Private Realities: The Psychology of Self-Monitoring, New York: W. H. Freeman.

Snyder M., Berscheid, E., and Glick, P. (1985). Focusing on the exterior and the interior: Two investigations of the initiation of personal relationships. Journal of Personality and Social Psychology, 48, $1427-1439$.

Snyder, M. and Gangestad, S. (1986). On the nature of self-monitoring: Matters of assessment, matters of validity. Journal of Personality and social Psychology, 51, 125-139.

Snyder, M. and Monson, T. C. (1975). Persons, situations, and the control of social behavior. Journal of personality and social Psychology, 32, 637-744.

Snyder, M. and Simpson, J. A. (1984). Self-Monitoring and dating relationships. Journal of Personality and Social psychology, 47, 1281-1291.

State of oregon (1990). Trends, January, 1990. Department of Human Resources.

State of Oregon (1988). Report of Criminal Offenses and Arrests.

United way of the Columbia-Willamette (1988). Directory of Human Services: Multnomah County, Portland, Oregon.

United Way of the Columbia-Willamette (1989). Self-Help Groups, Portland, oregon. 
APPENDIX 
Frequency of Subject Responses in

Direction of high SM on the SM scale

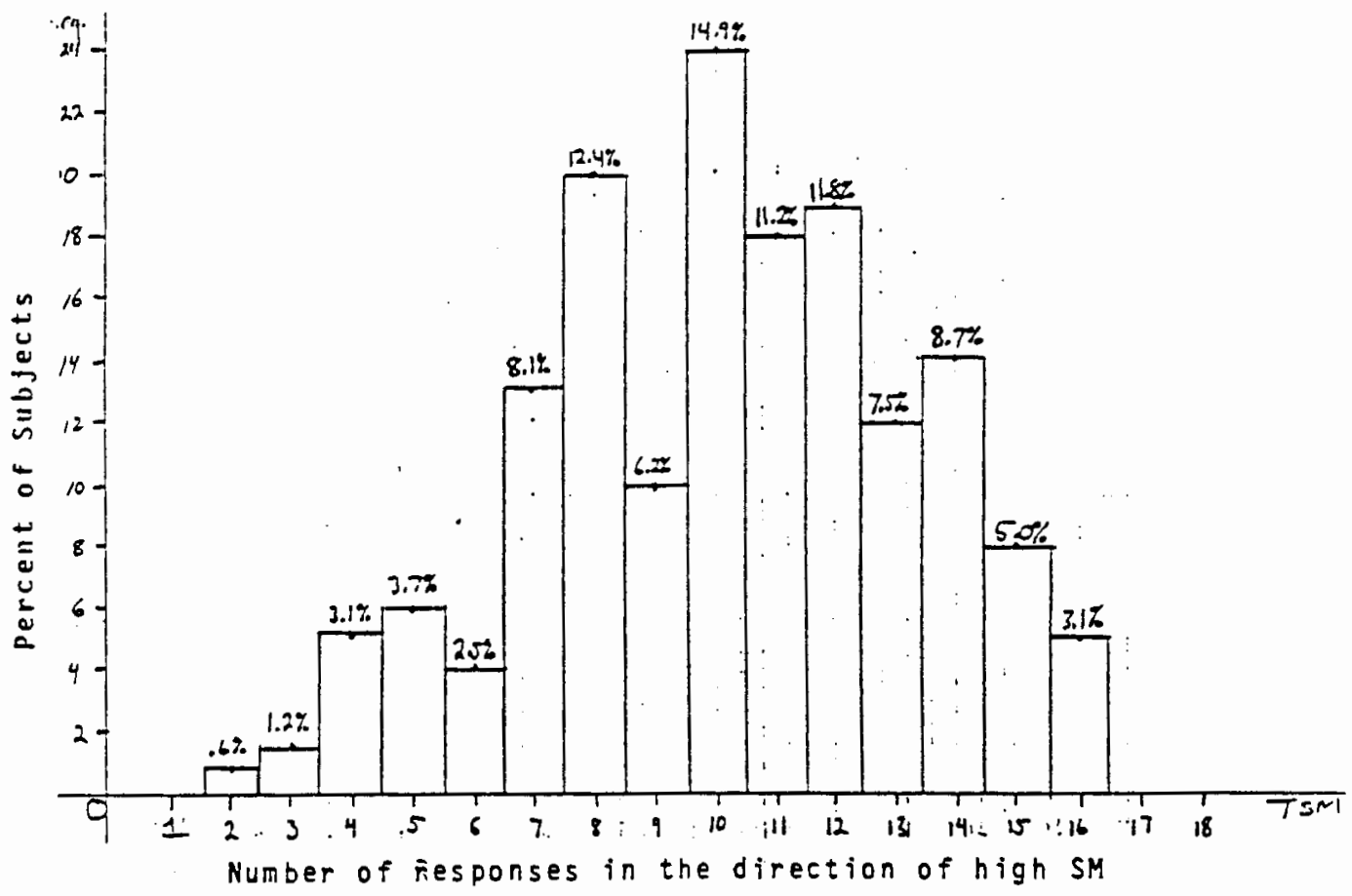

Mean Subject Response: 10.19255

$$
\text { Standard Deviation: } 3.12553
$$

\begin{tabular}{|c|c|c|c|c|}
\hline 蓜 & FIsquency & $P=r c: n t$ & $\begin{array}{l}\text { こUud=tive } \\
\text { ET=Quency }\end{array}$ & $\begin{array}{c}\text { Cumulative } \\
\text { purcanz }\end{array}$ \\
\hline 2 & 1 & 0.0 & 1 & E. 0 \\
\hline$=$ & 2 & 1.2 & 3 & 1.7 \\
\hline 4 & 3 & 3.1 & $y$ & 5.0 \\
\hline$\vdots$ & $=$ & 3.7 & I & 2.7 \\
\hline$\vdots$ & 4 & 2.5 & 18 & 12.2 \\
\hline 7 & $: Z$ & 3.1 & 31 & 25.3 \\
\hline$\therefore$ & 20 & 12.4 & $=1$ & 31.7 \\
\hline 4 & 20 & 5. ? & $=1$ & 37.5 \\
\hline 10 & 24 & 14.7 & 45 & 22.5 \\
\hline 1: & !s & il. 2 & 122 & 54.0 \\
\hline 12 & $i s$ & 11.3 & 122 & $7 \vdots 0$ \\
\hline$\therefore=$ & $i 2$ & 7.5 & 234 & $\approx د . ?$ \\
\hline 14 & $1 \div$ & $\therefore .7$ & $1 \rightarrow 0$ & 91.5 \\
\hline 15 & 0 & 5.6 & iso & $\overline{y c} \cdot y$ \\
\hline is & $\underline{s}$ & 5.1 & $1 \leqslant 1$ & 100.0 \\
\hline
\end{tabular}


Hypothesis (1): 12th grade site.

TABLE OF MFHILOS BY TSMHILO

MFHILOS TSMHILO

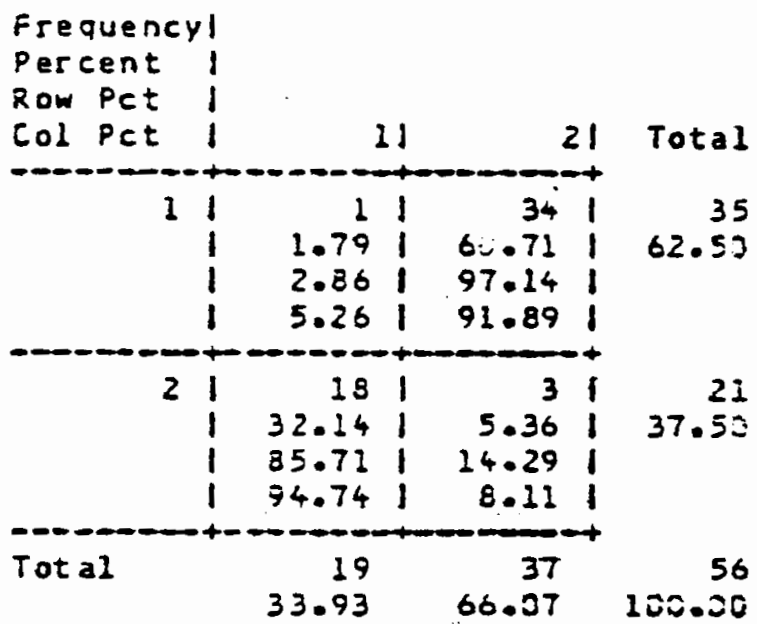

STATISTICS FDR TABLE OF MFHILOS BY TSMHILO

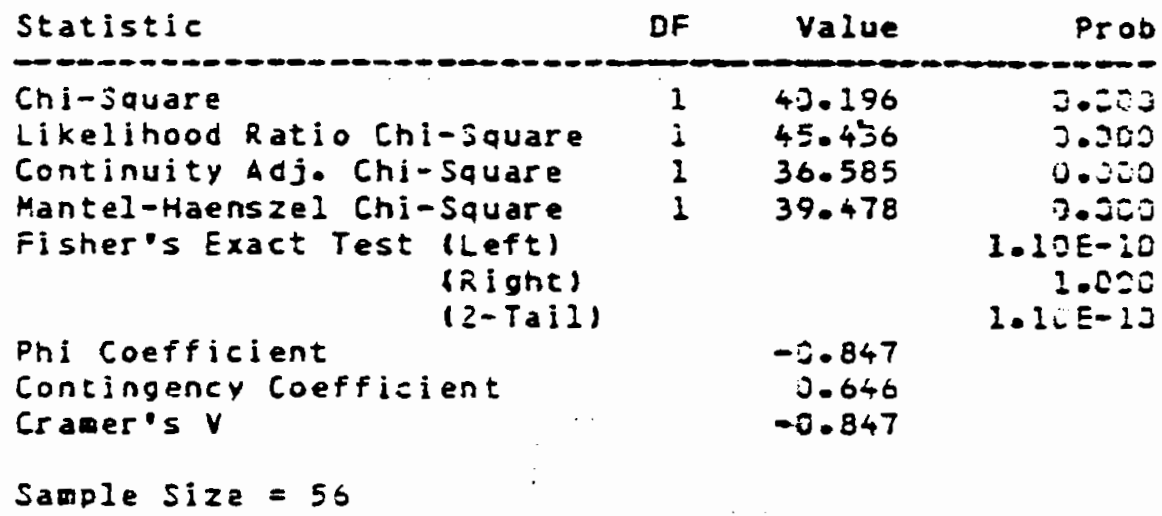


Hypothes is (1): Jail sites.

TABLE OF MFHILJS BY TSMHILLO

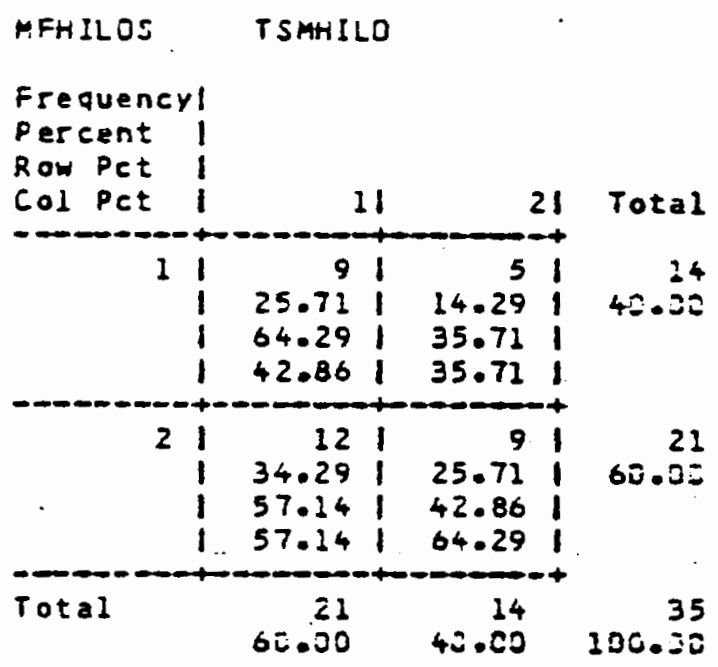

STATISTICS FOR TABLE OF MFHILOS BY TSMHILO -

\begin{tabular}{|c|c|c|c|}
\hline Statistic & DF & value & Prod \\
\hline $\begin{array}{l}\text { Chi-Square } \\
\text { Likelihood Ratio Chi-Square } \\
\text { Continuicy Adj. Chi-Square } \\
\text { Mantel-Haenszel Chi-Square } \\
\text { Fisher's Exact Test (Left) } \\
\text { (Right) } \\
\text { (II-Tail) }\end{array}$ & $\begin{array}{l}1 \\
1 \\
1 \\
\vdots\end{array}$ & $\begin{array}{l}0.175 \\
0.179 \\
0.005 \\
0.173\end{array}$ & $\begin{array}{l}0.673 \\
0.672 \\
8.944 \\
0.677 \\
0.786 \\
0.474 \\
0.737\end{array}$ \\
\hline $\begin{array}{l}\text { Phi Coefficlent } \\
\text { Contingency Coefficient } \\
\text { Cramer's } v\end{array}$ & & $\begin{array}{l}c .071 \\
2.071 \\
C .071\end{array}$ & \\
\hline
\end{tabular}


Hypothesis (1): Alternative School site.

TASLE DF MFHILOS BY TSMHILO

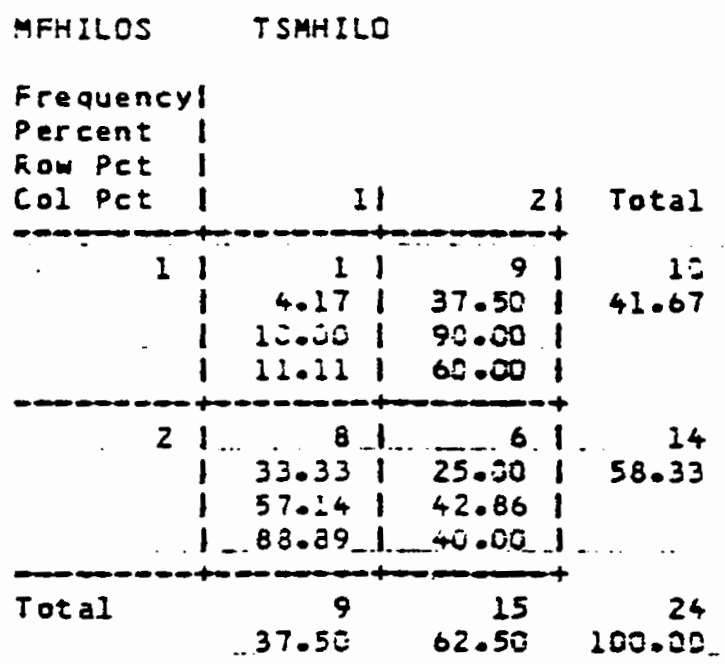

STATISTICS FOR TAZLE OF MFHILOS BY TSHHILO

\begin{tabular}{|c|c|c|c|}
\hline Statistic & DF & Value & Prob \\
\hline $\begin{array}{l}\text { Chi-Square } \\
\text { Likelihood Ratio Chi-Square } \\
\text { Continuity Adj. Chi-Square } \\
\text { Hantel-Haenszel Chi-Square } \\
\text { Fisher's Exact Test (left) } \\
(\text { Right) } \\
(2-T d i I)\end{array}$ & $\begin{array}{r}1 \\
1 \\
1 \\
1\end{array}$ & $\begin{array}{l}5.531 \\
6.132 \\
3.753 \\
5.301\end{array}$ & $\begin{array}{l}0.019 \\
0.213 \\
0.354 \\
0.321 \\
0.024 \\
6.998 \\
0.033\end{array}$ \\
\hline $\begin{array}{l}\text { Phi Coefficient } \\
\text { Contingency. Coefficient } \\
\text { Cramer's } v\end{array}$ & & $\begin{array}{r}-0.480 \\
0.433 \\
-0.480\end{array}$ & \\
\hline
\end{tabular}


Hypothes is (1): 9th grade site

TABLE OF MFHILOS BY TSMHILO

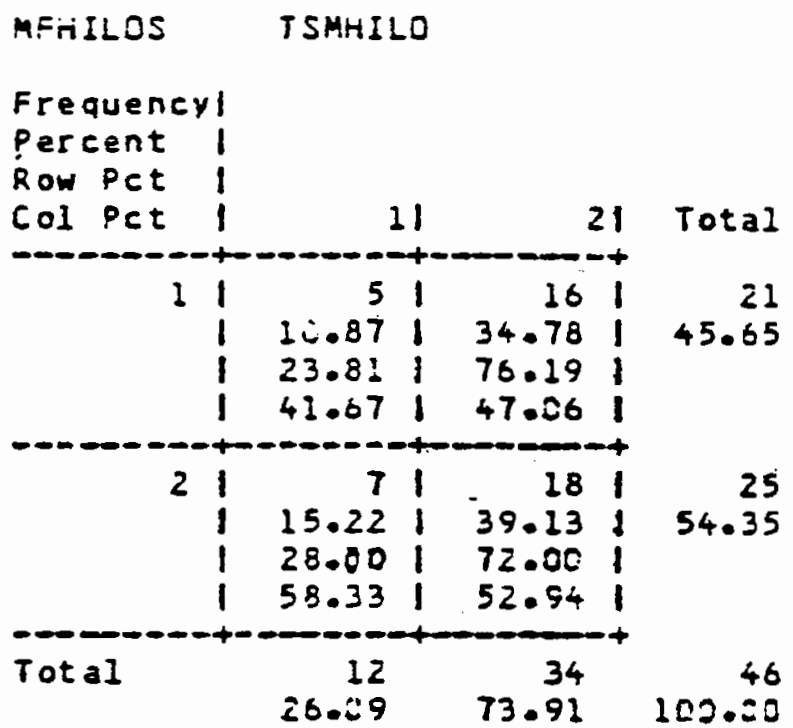

STATISTICS FOR TABLE OF MFHILOS BY TSMHILO

\begin{tabular}{|c|c|c|c|}
\hline Statistic & DF & Value & Prob \\
\hline $\begin{array}{l}\text { Chi-Square } \\
\text { Likelihood Ratio Chi-Square } \\
\text { Continuity Adj. Chi-Square } \\
\text { Mantel-Haenszel Chi-Square } \\
\text { Fisher's Exact Test (Left) } \\
\text { (Right) } \\
(2-T a i l)\end{array}$ & $\begin{array}{l}1 \\
1 \\
\vdots \\
1\end{array}$ & $\begin{array}{l}0.154 \\
2.134 \\
0.200 \\
0.102\end{array}$ & $\begin{array}{l}2.747 \\
-0.747 \\
1.020 \\
0.750 \\
0.508 \\
0.744 \\
1.000\end{array}$ \\
\hline $\begin{array}{l}\text { Phi Coefficient } \\
\text { Contingencr Coefficient } \\
\text { Cramer's } v\end{array}$ & & $\begin{array}{r}-0.048 \\
0.047 \\
-0.048\end{array}$ & \\
\hline
\end{tabular}


Hypothesis (1): A11 sites combined.

The SAS Systed

TA $3 L \equiv$ DF MFHILO BY TSMHILO

MFHILO TSMINILO

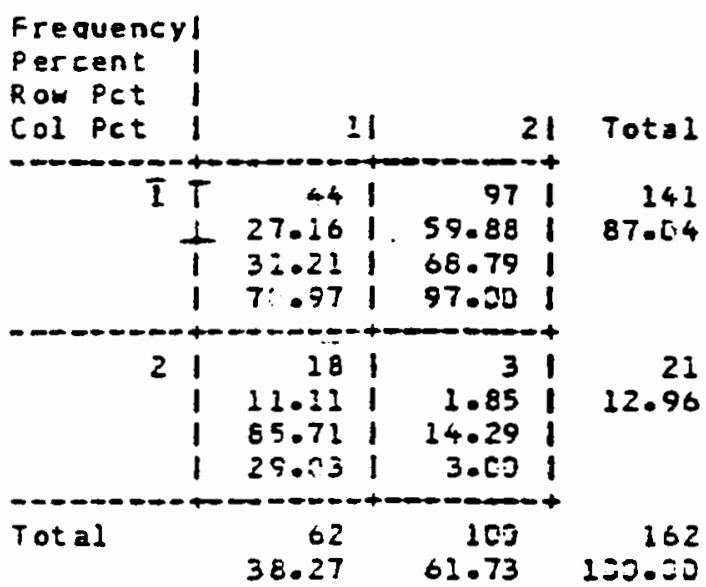

STATISTICS FOR T:BLE OF MFHILD BY TSMHILO

\begin{tabular}{|c|c|c|c|}
\hline statistic & DF & value & Prob \\
\hline 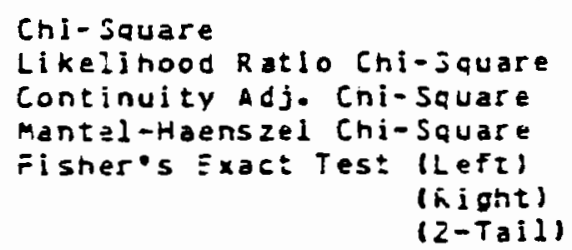 & $\begin{array}{l}1 \\
2 \\
1 \\
\vdots\end{array}$ & $\begin{array}{l}22.983 \\
23.312 \\
20.756 \\
22.546\end{array}$ & $\begin{array}{r}0.000 \\
0.000 \\
0.000 \\
0.000 \\
2.535-05 \\
\vdots .205 \\
2.5 j \equiv-56\end{array}$ \\
\hline $\begin{array}{l}\text { Phi Coefficient } \\
\text { Contingencr Coefficient } \\
\text { Cramer's } V\end{array}$ & & $\begin{array}{r}-2.377 \\
0.353 \\
-5.377\end{array}$ & \\
\hline
\end{tabular}


Hypothesis (5): 12th grade site.

TAILE OF TJMHILO SY TAREET

TSMHILJ TEREIT

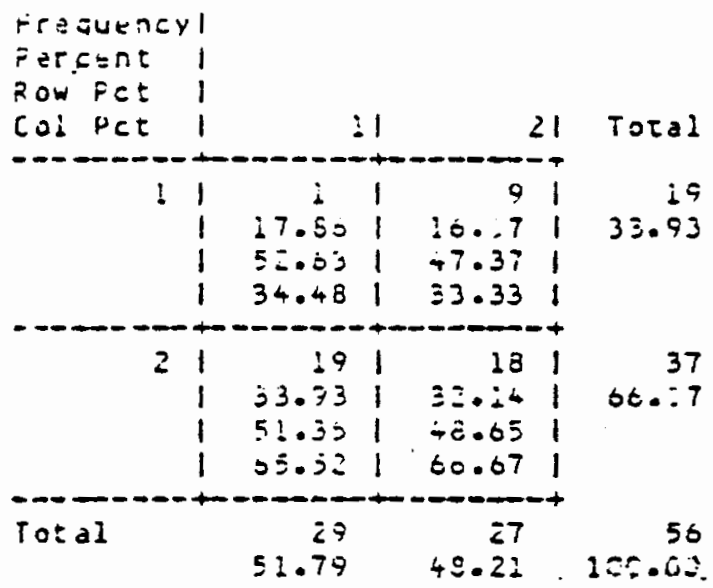

STATIETICJ FOR TAELS DF TZMHILO SY TARGET

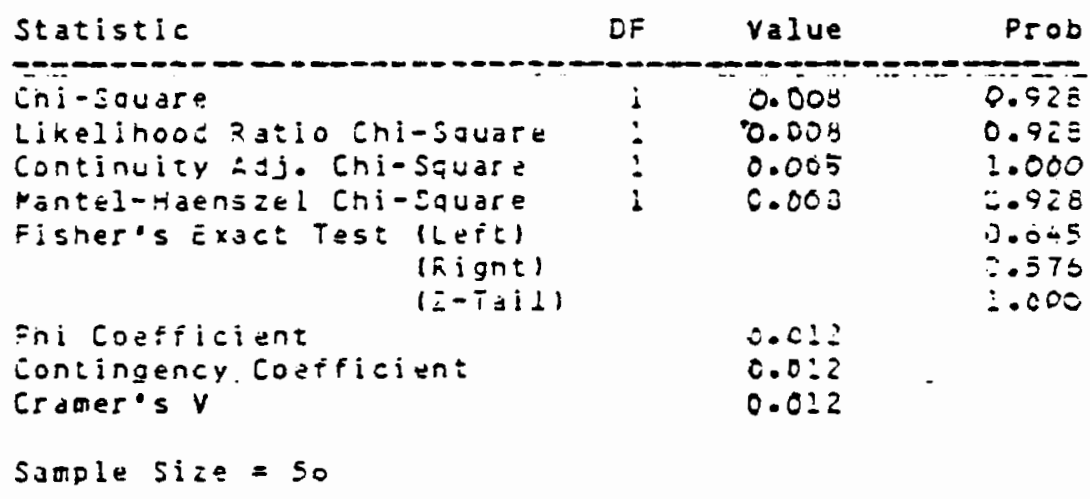


Hypothes is (5): Jail sites

TABLE OF TSMHILO B̈Y TAREET

TدMHID TR TAREDT

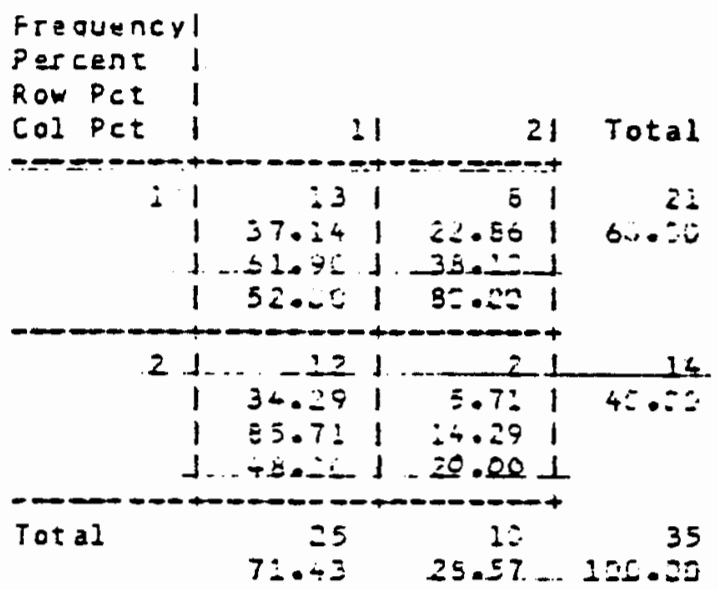

STATIZTICS FUR TABLE OF TSHHILO EY TARDET

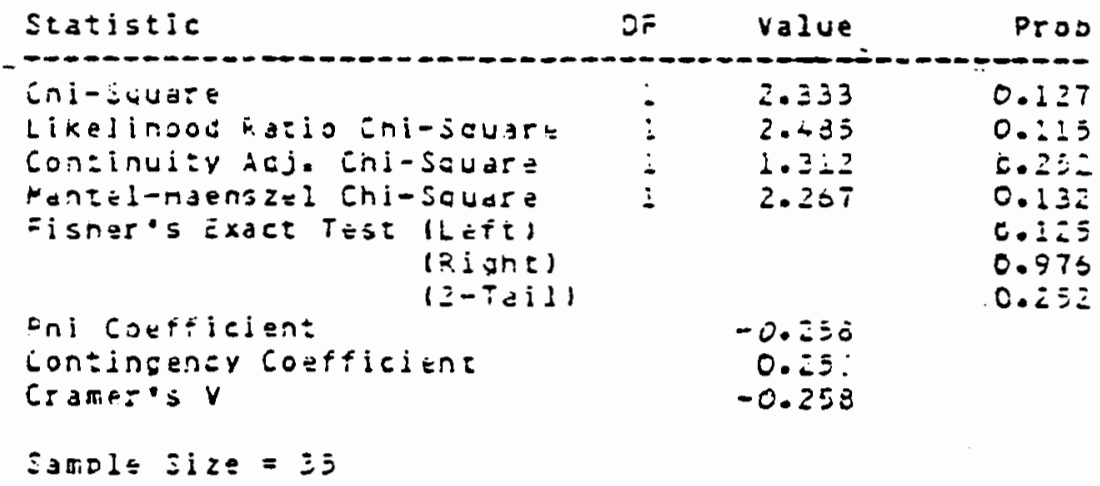


Hypothesis (5): Alternative school site.

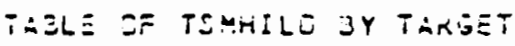

TMMHELO TARUET

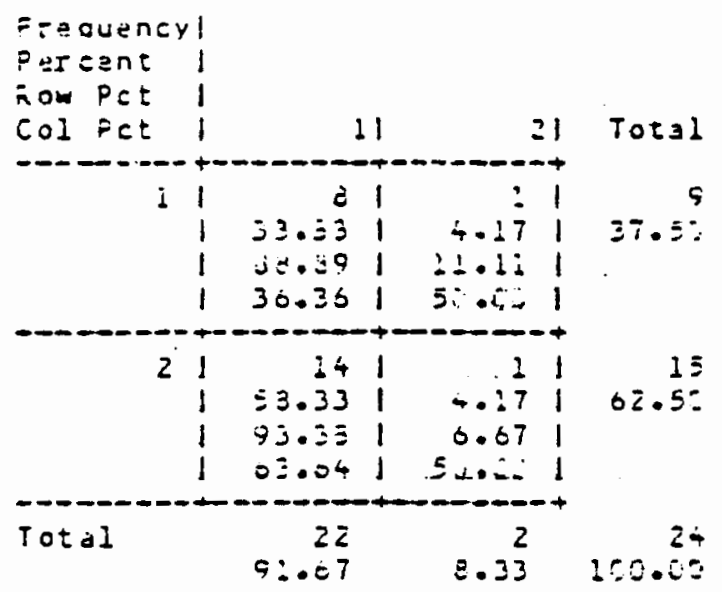

STATISTILS FJR TALLE OF TSMHILO SY TARGET

\begin{tabular}{|c|c|c|c|}
\hline Statistic & DF & value & Prob \\
\hline 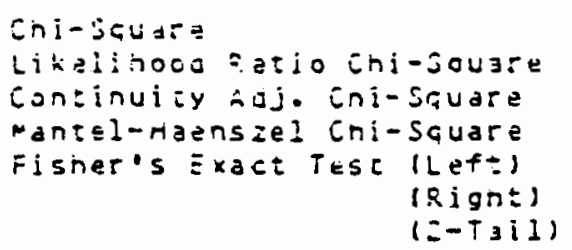 & $\vdots$ & $\begin{array}{l}0.1-5 \\
0.1+1 \\
0.000 \\
0.1 j 7\end{array}$ & $\begin{array}{l}0.703 \\
0.707 \\
1.000 \\
0.709 \\
0.020 \\
0.570 \\
1.000\end{array}$ \\
\hline $\begin{array}{l}\text { Pni Coeficient } \\
\text { Contingancy Cogfficient } \\
\text { Crames's } V\end{array}$ & & $\begin{array}{r}-0.075 \\
0.07 i \\
-0.078\end{array}$ & \\
\hline
\end{tabular}

Sample size $=24$ 
Hypothes is (5): 9th grade site.

TABLE OF TSMALLO BY TAREET

TEMHILJ TAREET

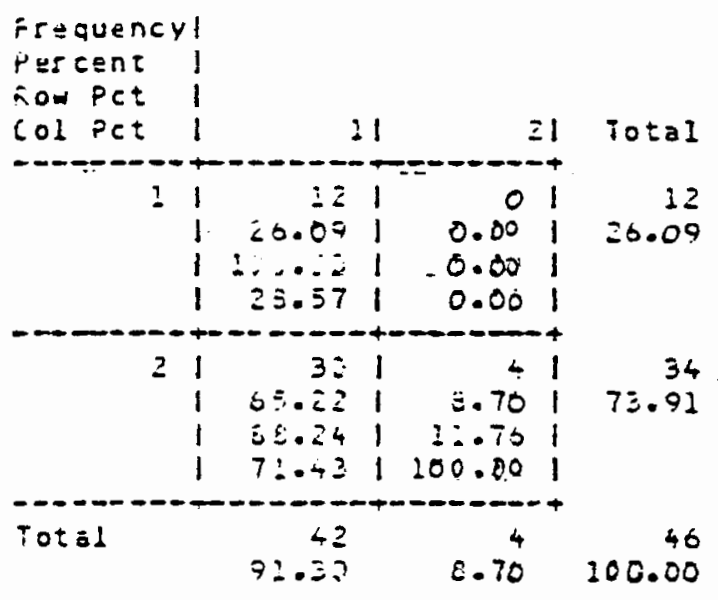

ETATIST:SS FJK TAELE JF TOMHELE EY TAREET

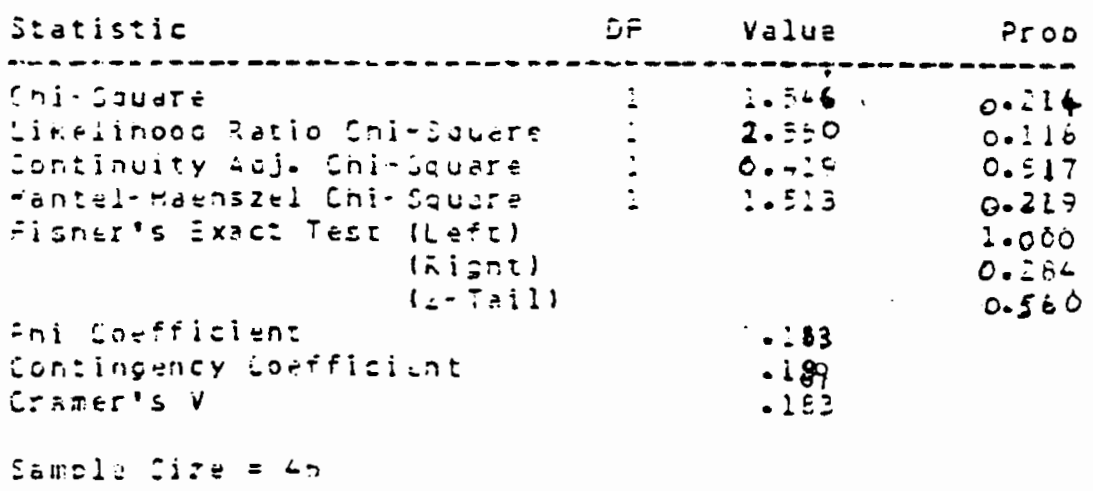


Hypothesis (5): All sites combined. As high SM scores increase selection of hypothetical date based on attractiveness will increase.

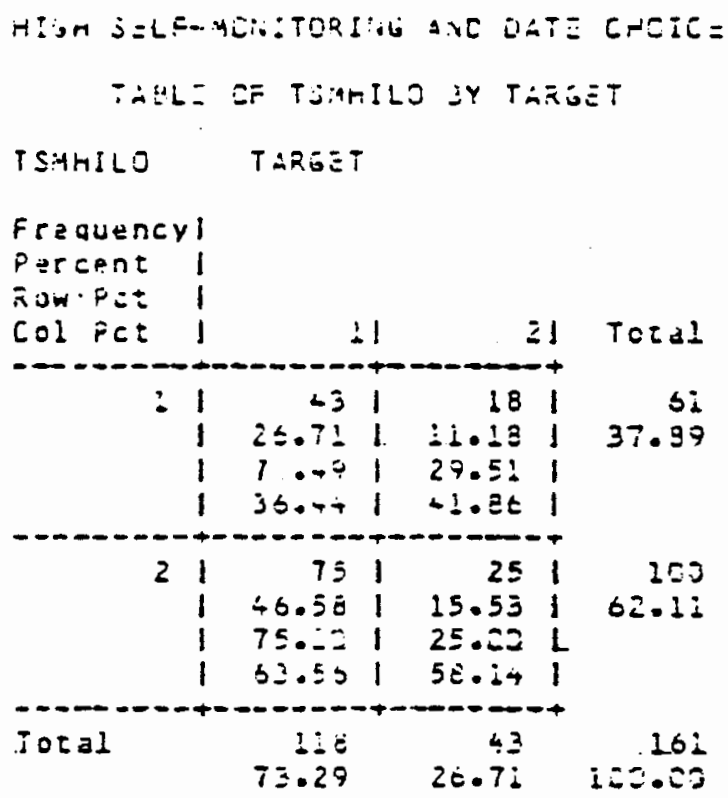

STATISTIES FOA TAELE OF TEMHILO EY TARGET

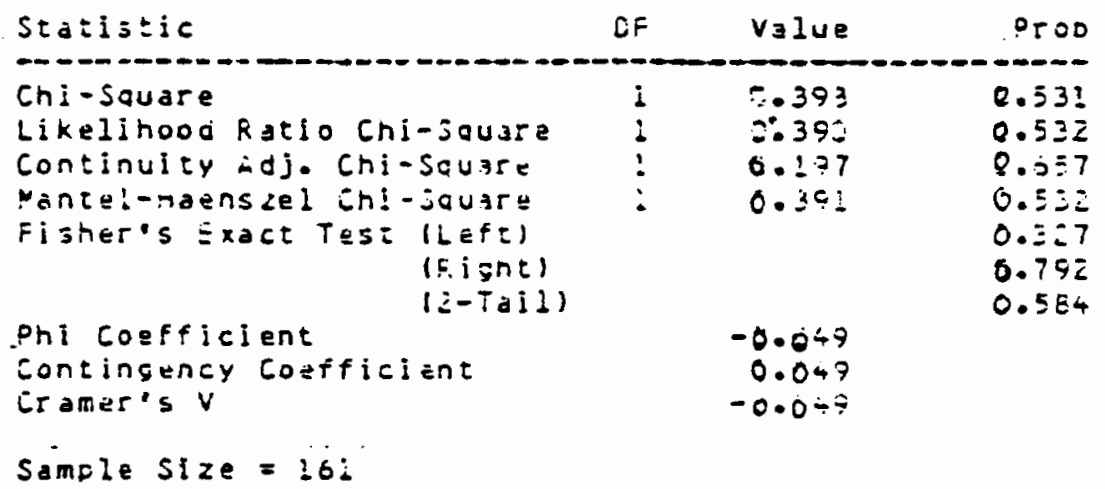


FUQ: Participation in the experiment with Question (1) on the FuR.

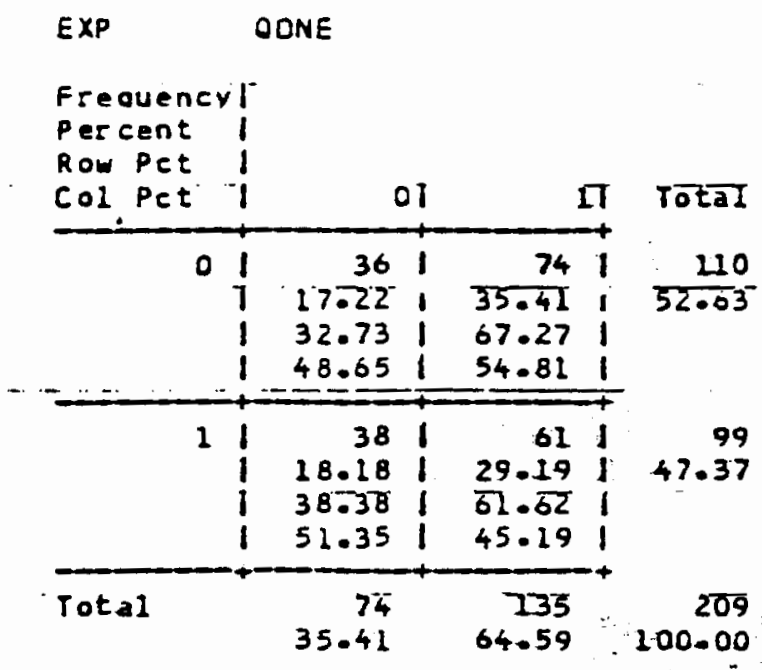

STATISTIES FOR TABLE OF EXP EY ODNE

\begin{tabular}{|c|c|c|c|}
\hline Statistic & DF & Value & PदOD \\
\hline $\begin{array}{l}\text { Chi-Square } \\
\text { Likelihood Ratio Chi-Square } \\
\text { Continuity Adi. Chi-Sauare } \\
\text { Mantel-Haensel Chi-Square } \\
\text { Fisher's Exact Test } \\
(\text { Left) } \\
\text { (Right) } \\
(2-T a i l)\end{array}$ & $\begin{array}{l}2 \\
1 \\
1 \\
1\end{array}$ & $\begin{array}{l}0.729 \\
0.729 \\
0.503 \\
0.725\end{array}$ & $\begin{array}{r}0.393 \\
0.393 \\
0.478 \\
0.394 \\
-0.239 \\
0.841 \\
0.469\end{array}$ \\
\hline $\begin{array}{l}\text { Phi coefficient } \\
\text { Contincency Coefficient } \\
\text { Cramer's } V\end{array}$ & & $\begin{array}{r}-0.059 \\
0.059 \\
-0.059\end{array}$ & \\
\hline
\end{tabular}


FUQ: Participation in the experiment with Question (2)

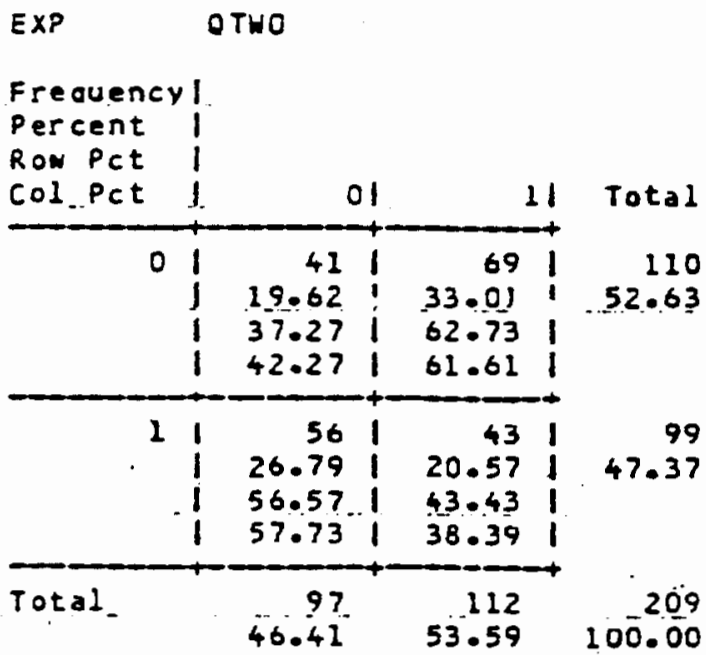

STATISTICS FOR TABLE OF EXP BY OTWO

\begin{tabular}{|c|c|c|c|}
\hline Statistic & DF & value & PrOD \\
\hline $\begin{array}{l}\text { Chi-Souare } \\
\text { Likelihood Ratio Chi-Sauare } \\
\text { Continultr Adl Chi-Sauare } \\
\text { mantel-Haenszel Chi-Sauare } \\
\text { Fisher's Exact Test (Left) } \\
\text { (RIght) } \\
(2-T a i I)\end{array}$ & $\begin{array}{l}1 \\
1 \\
1 \\
1\end{array}$ & $\begin{array}{r}7.798 \\
7.841 \\
7.042 \\
7.761\end{array}$ & $\begin{array}{r}0.005 \\
0.005 \\
0.008 \\
0.005 \\
3.92 \equiv-03 \\
0.998 \\
5.71 E-03\end{array}$ \\
\hline $\begin{array}{l}\text { Pni Coefficient } \\
\text { Contincencr Coefficient } \\
\text { Crawer's } v\end{array}$ & & $\begin{array}{r}-0.193 \\
0.190 \\
-0.193\end{array}$ & \\
\hline Samole size $=209$ & & & \\
\hline
\end{tabular}


FUQ: Participation in the experiment with Question (6)

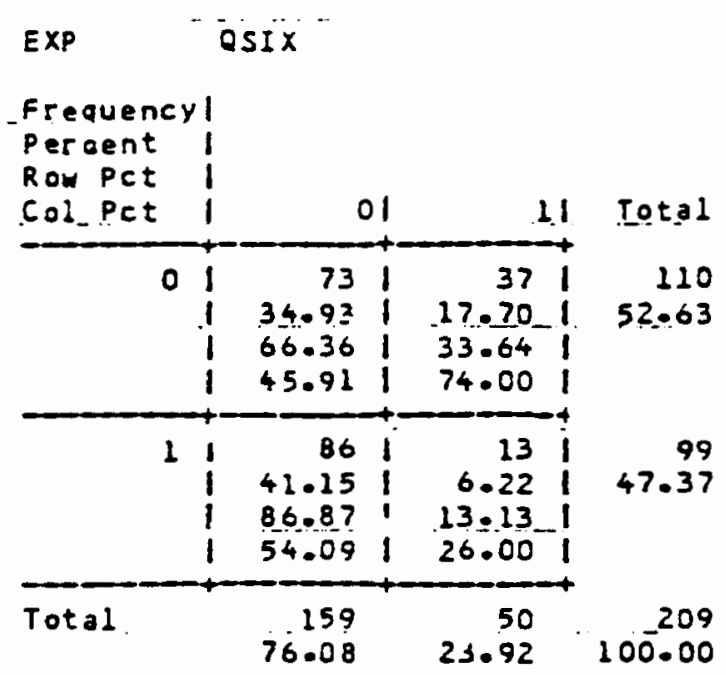

STATISTICS FOR TABLE OF EXP BY OSIX

\begin{tabular}{|c|c|c|c|}
\hline statistic . & DF & value. & Prob \\
\hline $\begin{array}{l}\text { Chi-Souare } \\
\text { Likelihood Ratio Chi-Square } \\
\text { Continuitr Adj. Chi-Sauare } \\
\text { Mantel-Haensel Chi-Sauare } \\
\text { Fisher's Exact Test (Left) } \\
\text { (Rloht) } \\
\text { (2-Tail) }\end{array}$ & $\begin{array}{l}1 \\
1 \\
1 \\
1\end{array}$ & $\begin{array}{l}12.037 \\
12.494 \\
10.937 \\
11.980\end{array}$ & $\begin{array}{r}0.001 \\
0.000 \\
0.001 \\
0.001 \\
3.925-04 \\
1.000 \\
5.95 E-04\end{array}$ \\
\hline $\begin{array}{l}\text { Phi Coefficient } \\
\text { Contingency Coefficient } \\
\text { Cramer's } v\end{array}$ & & $\begin{array}{r}-0.240 \\
0.233 \\
-0.240\end{array}$ & \\
\hline
\end{tabular}


FUQ: 9th graders versus 12 th graders and whether there were hints given by the experimenters.

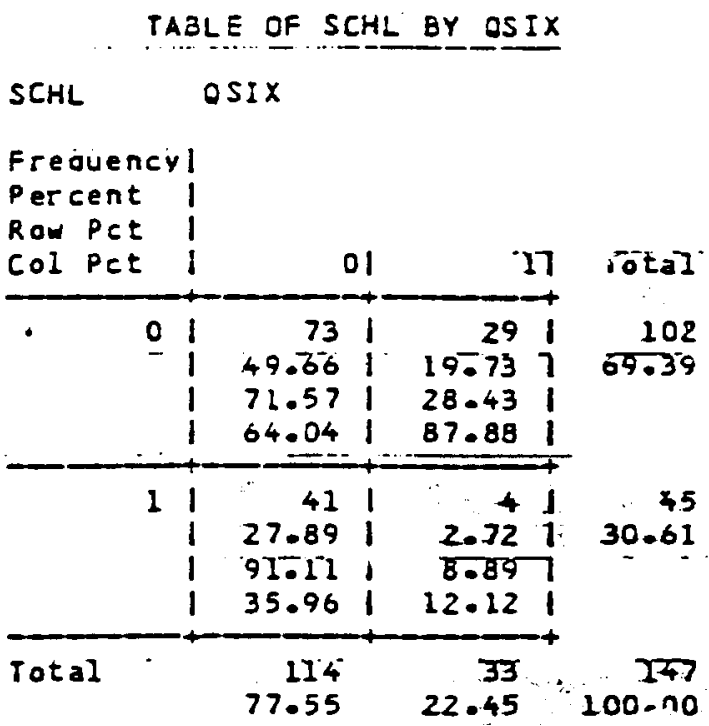

STATISTICS FOR TAELE OF SCHL BY OSIX

\begin{tabular}{|c|c|c|c|}
\hline Statistic & DF ${ }^{-\cdot}$ & $\sqrt{\text { alue }}$ & Prab \\
\hline $\begin{array}{l}\text { Chi-Square } \\
\text { Likelihood Ratio Chi-Square } \\
\text { Continuity Adi. Chi-Souare } \\
\text { Mantel-Haenszel Chi-Square } \\
\text { Fisher's Exact Test (Left) } \\
\text { (Riaht) } \\
\text { (2-Tail) }\end{array}$ & $\begin{array}{l}1 \\
1 \\
1 \\
1\end{array}$ & $\begin{array}{l}6.850 \\
7.784 \\
5.773 \\
6.803\end{array}$ & $\begin{array}{r}0.009 \\
0.005 \\
0.016 \\
0.009 \\
5.90 E-03 \\
0.999 \\
9.57 E-03\end{array}$ \\
\hline $\begin{array}{l}\text { Phi Coefficient } \\
\text { Contingency Coefficient } \\
\text { Cramer's } V\end{array}$ & & $\begin{array}{r}-0.216 \\
0.211 \\
-0.216\end{array}$ & \\
\hline
\end{tabular}

Samole size $=147$ 
FUQ: 9th graders versus 12 th graders on Question (1) of the FUQ.

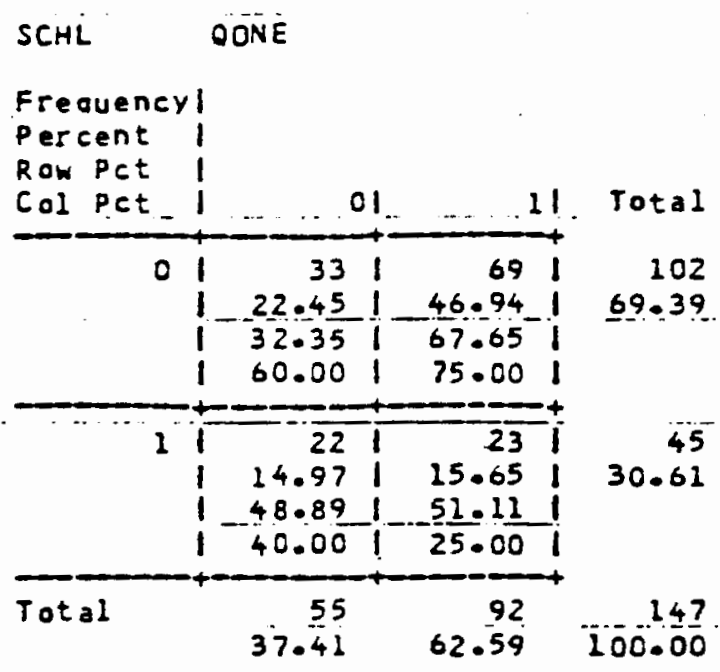

STATISTICS FOR TABLË OF SCHL BY OONE

\begin{tabular}{|c|c|c|c|}
\hline Statistic & DF. & Value & Prob \\
\hline $\begin{array}{l}\text { Chi-Square } \\
\text { Likelihood Ratio Chi-Square } \\
\text { Continuity Adj. Chi-Square } \\
\text { Mantel-Haenszel Chi-Sauare } \\
\text { Fisher's Exact Test (Left) } \\
\text { (Riont) } \\
(2-T a i l)\end{array}$ & $\begin{array}{l}1 \\
1 \\
1 \\
1\end{array}$ & $\begin{array}{l}3.646 \\
3.592 \\
2.974 \\
3.621\end{array}$ & $\begin{array}{l}0.056 \\
0.058 \\
0.085 \\
0.057 \\
0.043 \\
0.981 \\
0.066\end{array}$ \\
\hline $\begin{array}{l}\text { Phi coefficient } \\
\text { Continoencr Coefficient } \\
\text { Cramer's } v\end{array}$ & & $\begin{array}{r}-0.157 \\
0.156 \\
-0.157\end{array}$ & \\
\hline Sample size $=147$ & & $\cdot$ & \\
\hline
\end{tabular}


FUQ: 9th graders versus 12 th graders on whether there was an overall school effect.

TABLE OF JCHL BY COMSCHL

SCHL COMSCHL

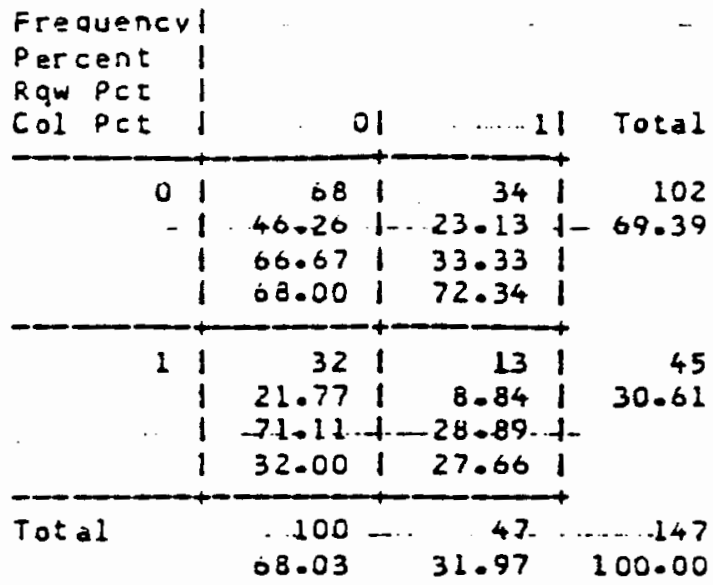

STATISTIES FOR TAELE OF SCHL BY COMSCHL

\begin{tabular}{|c|c|c|c|}
\hline statistic & $D F$ & Vaive & Prob \\
\hline $\begin{array}{l}\text { Chi-Souare } \\
\text { Likelihood Ratio Chi-Saware } \\
\text { Continuity Adi. Chi-Souare } \\
\text { Mantel-raenszl Chi-Souare } \\
\text { Fisner's Exdet Test }(\text { Left) } \\
\text { (Right) } \\
(2-T a i l)\end{array}$ & $\begin{array}{l}1 \\
1 \\
1 \\
1\end{array}$ & $\begin{array}{r}0.284 \\
.0 .287 \\
0.116 \\
0.292\end{array}$ & $\begin{array}{l}0.594 \\
0.592 \\
0.733 \\
0.596 \\
0.370 \\
0.764 \\
0.702\end{array}$ \\
\hline $\begin{array}{l}\text { Pni coefficient } \\
\text { Contingencr Coefficient } \\
\text { Cramer's } V\end{array}$ & & $\begin{array}{r}-0.044 \\
0.044 \\
-0.044\end{array}$ & \\
\hline
\end{tabular}


FuQ: 9th graders versus 12 th graders and whether there was an overal] experiment influence:

TAJLE OF SCRL OH COMAEXP

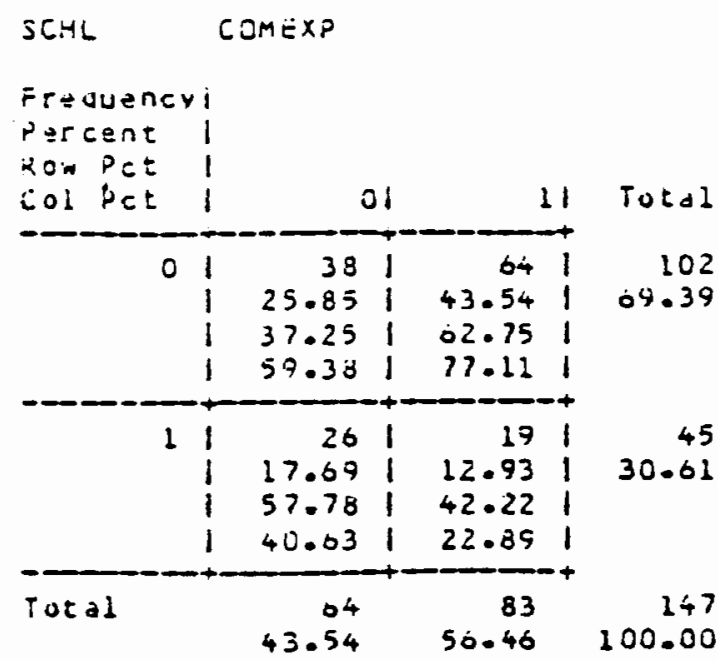

STATISTILS FCR TABLE LF SCHL EY COMEXP

\begin{tabular}{|c|c|c|c|}
\hline it 3 tistic & $O F$ & value & Prod \\
\hline $\begin{array}{l}\text { Chi-joudre } \\
\text { Likelihood Ratio Cni-Square } \\
\text { Continuity Adi. Chi-Sauare } \\
\text { Mantei-Haenszel Chi-Souare } \\
\text { fisner's Exact Test }(\text { Left) } \\
(\text { Rignt) } \\
(2-T a i l)\end{array}$ & $\begin{array}{l}1 \\
1 \\
1 \\
1\end{array}$ & $\begin{array}{l}5.350 \\
5.332 \\
4.548 \\
5.314\end{array}$ & $\begin{array}{l}0.021 \\
0.021 \\
0.033 \\
0.021 \\
0.017 \\
0.994 \\
0.030\end{array}$ \\
\hline $\begin{array}{l}\text { Phi Coeificient } \\
\text { iontincency Coeficient } \\
\text { Cramer's } V\end{array}$ & & $\begin{array}{r}-0.191 \\
0.127 \\
-0.191\end{array}$ & \\
\hline
\end{tabular}


Interviewets script.

These are pictures of students at a nearby school.

We are interested to find out how you would pair these people up if they were dating.

Look at the pictures and information provided. They have rated themselves on personality, sense of humor, and their interests.

on the scale, 9 is high, $I$ is low.

I want to see how you would make up boy/girl couples that you think would be the most compatible.

Please tell me when you have made the five matches.

I have some true/false questions for you to answer. There are no right or wrong answers.

In order for everybody to have an equal chance to answer the questions, I am going to ask you to wear these headphones.

The questions will be asked one at a time. You will have time to answer the questions.

Are you ready?

(Subjects are given headphones and answer questions.)

Here are the boys/girls you looked at in the study.

(subjects are shown photographs.)

Who would you like to date?

On a scale of 1 to 9 ( 9 being high), how would you rate yourself on attractiveness, sense of humor, and personality? 
From the information on interests provided on the cards, choose the one that appeals to you most.

Do you have any questions?

Thanks for helping.

Please don't discuss this with other students until all have completed their questionnaires. 


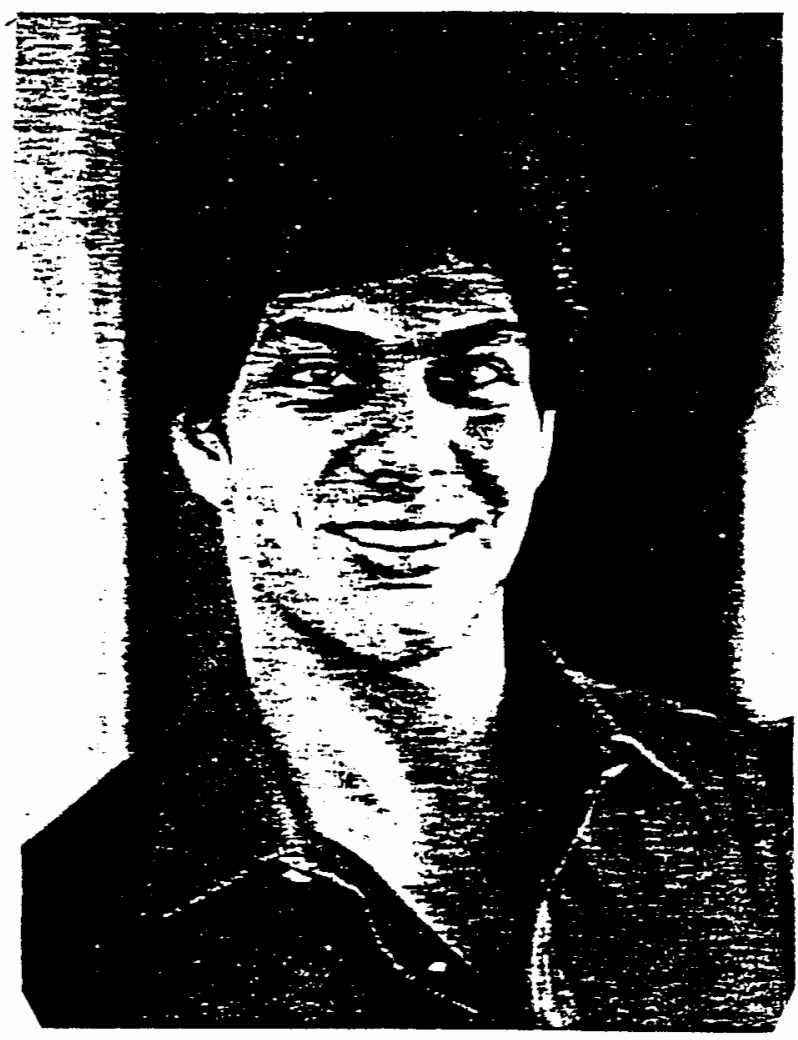

Self-ratings by individual

High $=9$ Low $=1$

$\begin{array}{lc}\text { Sense of humor } & 2 \\ \text { Personality } & 3 \\ \text { Interest } & \text { Television }\end{array}$




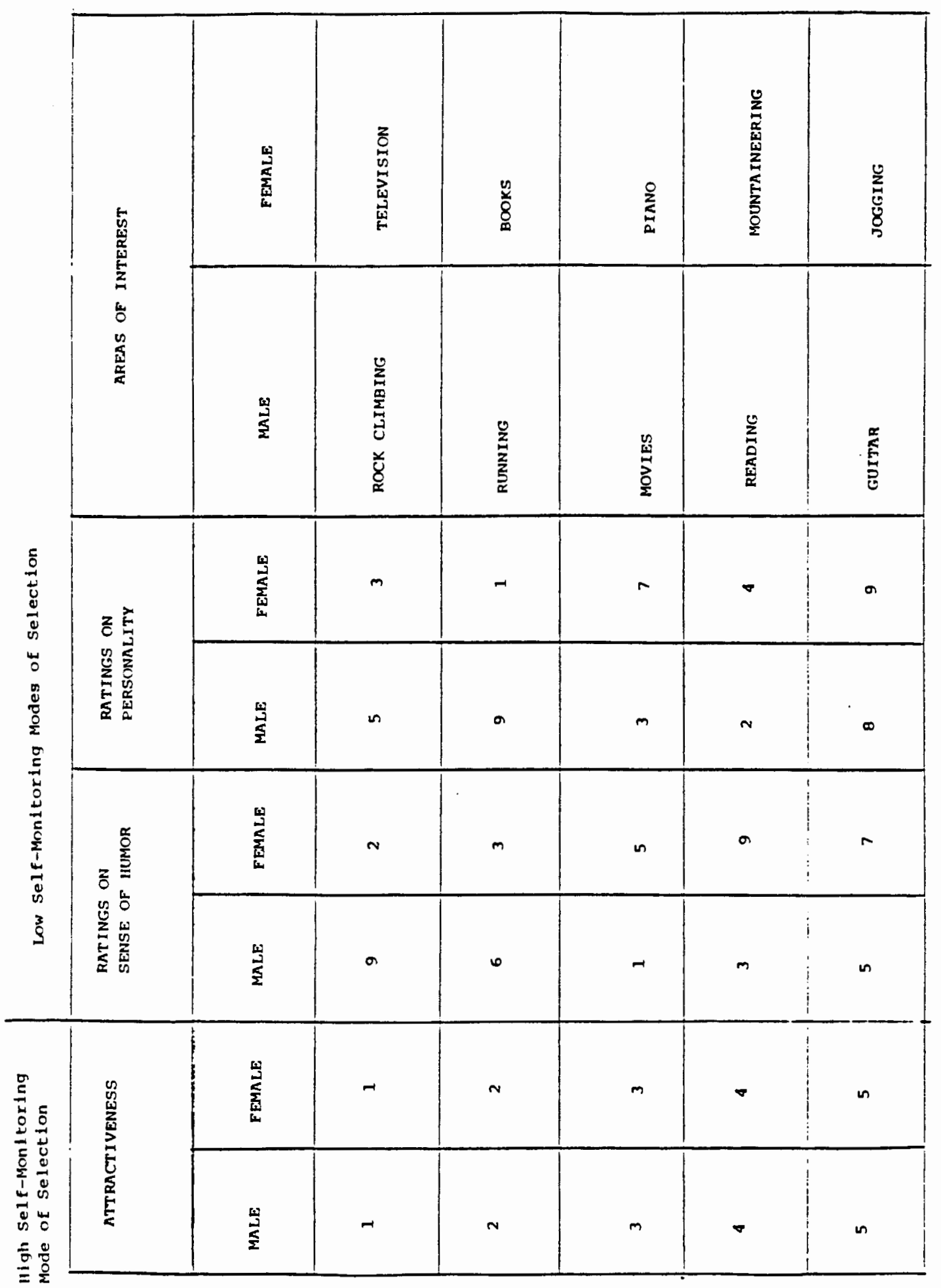




\section{Self-reported interests}

$\begin{array}{ll}\text { Rock climbing } & \text { Television } \\ \text { Running } & \text { Books } \\ \text { Movies } & \text { Piano } \\ \text { Reading } & \text { Mountaineering } \\ \text { Guitar } & \text { Jogging }\end{array}$


Dear Firent/Guardian,

and Fortland State University are presenting a unit on how Fisychological Experiments are conducted. The goals of the unit will be to: (1) provioe information on the design of a psvehological experiment, how the experiment is mun and how the results may be useful, and ( 2$)$, ofier the stuoents an opfortunity to papticipate in such a pevchological experiment.

Mr. Velneim, a graduate student at Fortland 5 tate University. is conducting researen through Fortland State University on atiltude of youth and wavs they make oecisions. The information collected mey be Liseful to determine the best ways to worle with youth in small groufs and one-on-one.

We will ask: the student to look at pictures of young men and womer and hesr some information about each one. Then we will ask: students to pick: which of the fictured men and women would make good soupies. The students will also answer a short true/false 18-item questionaire. In all, 10 minutes of time will be asked of each stident.

All information given and the identities of all those Farticipating will be kept in strictest confidence. Though participation is encouraged, it is not required. and the student will rot be penalized in any way for not participating.

This project has been reviewed by the school administration. If you have any questions, plesse feel free to call the or Mr. Oelheim at o44-7e12. The cooperation and participation of your chilg wolld be greatly appreciated.

Yours sincerely,

F._Iseil I. Gelheim

If you or your cnild experience any prodiems as a resuli of Ferticifation in this project, please contact the chair of tme Human Sub jects Fieview Committee, Ditice of Grants and Contrats, Joz Cramer Heil. Fortiand Stete University, 725-34i7.

has

PErmissior tu fartielfete in the Etudy erititied "Environmerital and Age Differances in the Formation of Fomantic Fialrs and Seit-Monitoring in Adoleseents" conducteo Linder the supervision of FLIESEl 1 Delheim arid Fortiand State Liniversity. 


\section{Informed Lonsent}

I, - hereby agree to fanticifate as

a subject in the study entitled "Environmental arid age Ditterences in the Formetion of Fomantic Fairs and Self-Monitoring in faolescents conoucted urider the supervision of Fussell Deliheim.

I understand that the study involves mailing-up coupies based on fictures and bio-dita given, and thie completian ot a le item questionalre.

I Linderstarid that this procedure ls part of a 5 lass urit or. Expenimental fisysnological Methods and thet I will be required to give 10 minutes of $m y$ tame to compiete the procedure if I chooje to farticipate. If I elect not to farticipate in this fart of the unit I will not be penalized iri any way.

It hias been explained to me that the purpose of this study is to learn first hand about psychological experimental procedures. ano to contribute data about tne emmergenes of selt-monitoring in adclesこents.

I may not receive any dimect benetit from participacion in this study other than to increase my bnowledge about psychological experlmerital methous, but my farticifation may neif to increase knowledge which may benetit others in the future.

Mr. Gelheim has offered to answer any questions 1 may have about the study and whiet is expected ot me in the study. I have beer.

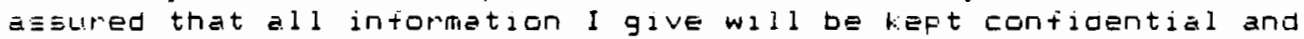
nel ther my riame nor identity will be lised for plitlication or futlic discussion purposes.

I understand that I am tree to withdraw from particifation in this study at any time without jeofandzzing my coures grade or my reiatioriship with the school.

I have read arid understand the forgoing lritumation and agree to Fatrateipate iri this study.

Uate

SIgnatLIVE

If you experience prodems that are the result of your participation in this etudy, please coritact the Enair ot the Humen Sutjects fieview Comalttee, Jffice of Erants arid Conitracts, JuS Cramer Hall, Fortland Stat= University, 72:5-5417. 